Sharif University of Technology
Scientia Iranica
Transactions E: Industrial Engineering
hCIENTIA

\title{
Integrated supply chain decisions with credit-linked demand: A Stackelberg approach
}

\author{
C. Zhang ${ }^{\mathrm{a}}$, M. You ${ }^{\mathrm{a}}$, and G. Han ${ }^{\mathrm{b}, *}$ \\ a. School of Management, Nanjing University of Posts and Telecommunications, 66 Xin Mofan Road, Nanjing, P.R. China, 210003. \\ b. School of International and Public Affairs, Shanghai Jiao Tong University,1954 Huashan Road, P.R. China, 200030. \\ Received 25 January 2018; received in revised form 29 March 2019; accepted 21 July 2019
}

\author{
KEYWORDS \\ EOQ model; \\ Supply chain \\ coordination; \\ Stackelberg model; \\ Trade credit; \\ Credit-linked demand.
}

\begin{abstract}
Market demand is likely to be affected by the seller's credit in many industrial practices. In this respect, the present study aims to investigate the beneficial performance of the supply chain in terms of credit-linked demand. Without loss of generality, this study was conducted under three different decision circumstances, namely supplier dominated, retailer dominated, and centralized supply chains. In this paper, a demand model was developed as a function of the trade credit period. While the supplier determines the optimal trade credit period, the retailer determines the optimal replenishment cycle time. In such conditions, first, optimal solutions were suggested for both centralized and decentralized decisions in a supplier Stackelberg model and a retailer Stackelberg model, respectively. Then, a set of theorems was developed to determine the optimal results. Finally, a numerical example and sensitivity analysis were provided to illustrate the efficiency of the proposed models and optimal solutions. The findings revealed that under the trade credit condition, the supplier-dominated supply chain outperformed the retailer-dominated one. However, in case supplier did not provide the trade credit period, the result would be the opposite.
\end{abstract}

(C) 2021 Sharif University of Technology. All rights reserved.

\section{Introduction}

In Economic Order Quantity (EOQ) model, retailers are often supposed to pay immediately after receiving the goods. However, suppliers usually offer the retailers a trade credit period to enlarge the market demand and occupy lot size in many industrial practices. Trade credit is a significant source of external financing. According to the Financial Times, trade credit accounted for $90 \%$ of global merchandise trade in 2007 with the total amount of $\$ 14$ trillion [1]. Then, as of June 2016, the application of trade credit was 1.3 times that of

*. Corresponding author. Tel.: 086-13524287915

E-mail address: hanguanghua@sjtu.edu.cn; (G. Han)

doi: $10.24200 /$ sci. 2019.50342 .1646 bank loans on the total balance sheet of non-financial business in the United States [2]. In Fortune, Quick [3] reported that some large enterprises such as Procter and Gamble, Unilever, Merck, Mondelez International implemented a policy through which retailers could use trade credits of 120 days to delay payments to suppliers.

When a supplier offers trade credit to allow its retailers to postpone payments, the retailer can sell products and deposit income from the sale in the bank during the trade credit period. However, if the retailers fail to pay up during the trade credit period, a higher interest is then charged by the supplier. On the contrary, during this period, the retailer can earn interest while suppliers lose the interest they could have earned. Currently, strong evidence shows that trade credit is a significant short-term financial strategy. For 
example, Wal-Mart Store Inc and Carrefour Gome (a large European home appliance chain retailer) often delay payments to their suppliers due to their market powers in the supply chain. In this respect, WalMart and Carrefour Gome can make reasonable use of sales revenue to obtain additional interest. Therefore, the trade credit period is of economic significance to the retailers in terms of delaying the replenishment settlement until the last moment of the trade credit period.

Since the supplier and retailer make their decisions over time, mathematical models are formulated in the Stackelberg game process under different supply chain structures. For a supply chain with the background of Stackelberg game characteristics, each member in the supply chain aims to maximize one's own profit and make own decisions independently and rationally. For example, Toyota and General Motors are giant manufacturers and leaders in the world market who can considerably impact the decisions of other members in the supply chain. In addition, other gigantic retailers, with their own remarkable power in their market, play leading roles and act like the channel leaders, including Tesco, Gome, and Wal Mart. In fact, both supplier-dominated and retailer-dominated supply chains aim to maximize their own profit and the total profit of the supply chain.

The following research questions are investigated in this paper:

1. Under the decentralized and centralized decision instances, what are the optimal trade credit period and replenishment cycle time and how can they be compared?

2. How the optimal decision variables affect the expected profits of all supply chain members in three supply chain structurers?

3. Under the decentralized decision, which one is more beneficial to the supply chain, the Supplier Stackelberg (SS) model or Retailer Stackelberg (RS) model?

To address the above three questions, this paper considered both decentralized and centralized decisions simultaneously based on the assumption that the demand was related to the trade credit period. Both the trade credit period offered by the supplier and the retailer's replenishment cycle time are considered to be decision variables in the proposed model. Furthermore, to fully understand the impacts of different structures on the performance of supply chain, the following factors were taken into account: (1) Suppliers usually allow retailers to delay payment, while the retailers do not provide trade credit period to customers; (2) The trade credit period offered by the supplier is positively correlated with the annual demand rate; (3) The profits of both supplier and retailer are considered; (4) The respective effects of trade credit period and retailer's replenishment cycle time on optimal decisions under different decision-making structurers are investigated, respectively; (5) The decisions of the supply chain members under three different structures: (i) Supplier Stackelberg (SS), (ii) Retailer Stackelberg (RS), and (iii) centralized decision are explored. Then, proper conditions that could facilitate searching for optimal solutions for both supplier and retailer under different structures were derived. In addition, some theorems were developed to reflect the retailer and supplier's decision concerns. Finally, the equilibrium solutions and numerical examples were given for further some management inspiration.

The rest of this paper is organized as follows. Section 2 discusses the literature review. Section 3 presents the notations and assumptions. Section 4 formulates the supplier's and retailer's model. Section 5 introduces the centralized and decentralized inventory models in Stackelberg games. Section 6 provides a numerical example and sensitivity analysis to investigate the effects of the trade credit period and retailer's replenishment cycle time on the Supply Chain (SC) performance. Section 7 concludes the study and discusses the issues for future research.

\section{Literature review}

Over the last five decades, a number of researchers have drawn their attention to trade credit period. In 1967, Beranek [4] pointed out the significance of trade credits when determining order lot size. Goyal [5] was the first one who studied the EOQ model under trade credit conditions. Later, many other scholars have extended the subject and studied the trade credit strategies. For instance, Jamal and Wang [6] extended Goyal's model [5] with the consideration of shortages. Moreover, Dye [7] referred to demand as a function of stock and made an assumption of trade credit in the model. Huang [8] developed an EOQ model under the condition of trade credits and suggested that in case the order quantity was smaller than the predetermined quantity, the supplier could provide partial allowable deferred payment to retailer. Huang and Hsu [9] studied the retailer's inventory policy when suppliers offered partial trade credit to its retailers. Gupta and Wang [10] proposed a stochastic inventory model under the assumption of trade credit. Jaggi and Kausar [11] determined the optimal solutions for retailers considering the credit-related demand function and proposed an optimal replenishment strategy for vulnerable items. When demand was related to credit period, Jaggi et al. [12] examined the optimal replenishment cycle time and credit period using EOQ model. Teng et al. [13] suggested that the demand rate was an incremental 
function of time under the trade credits assumption. Kumar Sett et al. [14] studied a two-warehouse inventory model in which the goods deteriorated as a result of increase in demand and change in time. Jaggi et al. [15] developed a new inventory model for incomplete quality items to optimize total profit and orders under delayed payment because in the real environment, there might be some defects in an order batch. Lou and Wang [16] established an EOQ model and did not account for the retailer's interests and supplier's increased capital opportunity cost through the provision of trade credit period.

Then, Wang et al. [17] extended the model of Lou and Wang [16] to consider the loss of capital opportunity during the trade credit period. Teng et al. [18] extended the retailer's EOQ model under conditionally deferred payment and proposed a new and simple arithmetic geometry method to establish optimal solutions. Kumar and Triphthi [19] took into account the inflation and exponential demand rate for deteriorating items in their model. Jaggi et al. [20] developed an inventory model for minimizing the costs incurred for retailers in different scenarios and established the optimal replenishment cycle length and storage period simultaneously. Considering the vendor offering credit period to the retailer, Khanna et al. [21,22] set up an integrated vendor-retailer inventory model that incorporated substandard products. Then, allowing for delayed payment, they developed an inventory model for retailers dealing with the deteriorating substandard products in which the order quantity and stock shortage were optimized by maximizing the expected total profit. In 2016, by means of the trade credit policy of price-dependent demand and consideration of shortage and complete backlog, Khanna et al. [23] set up an inventory management system model for deteriorating substandard products.

Recently, Peura et al. [24] examined whether suppliers could obtain the benefits of trade credit through a horizontal channel. They found that in case customers attach importance to trade credit, a financially stronger firm with trade credit could not only exclude its weaker competitor from the market but coordinate supply chain and fulfill the function of balancing contract. Chen and Zhang [25] studied the capital flow constraints and trade credit in lot sizing problems and concluded that incorporating the capital flow constraints and trade credit into lot sizing problems could affect the optimal solutions. Jaggi et al. [26] developed a retailer inventory model by considering the imperfect quality and deterioration with trade credit and examined both optimal trade credit period and length of a replenishment cycle. In the same year, Jaggi et al. [27] proposed an inventory model for retailers dealing with deteriorating substandard products with a certain credit period. In their study, the demand was assumed to increase exponentially and the backlog rate was inversely proportional to the waiting time for subsequent replenishment. They could jointly optimize the shortcomings and cycle length. Kouvelis and Zhao [28] examined the effect of credit rating on the optimal decisions of a supply chain when both the supplier and retailer were capital constrained. Feng et al. [29] developed a joint economic lot-size model to examine the integrated production-inventory policy for a product in deterioration and credit period. Their obtained results showed that suppliers could benefit from working with good ratings retailers, while retailers would prefer to cooperate with suppliers outside of their credit rating loopholes. However, all the abovementioned papers considered only the retailer's or supplier's profit or cost issues.

The papers already mentioned examined the trade credit period from the perspective of the trade credit providers. However, only a few studies took into account the trade credit period from the game perspective. In practice, some researchers have developed game-theoretic models to solve the interactive optimization problems both suppliers and retailers were facing. For instance, Zhou and Zhou [30] employed an EOQ model on the basis of the provision of unconditional and conditional trade credit under a supplierStackelberg model. In addition, Chern et al. [31] extended Lou and Wang's [16] model and obtained optimal equilibrium solutions by proposing a vendorStackelberg model. Hoseininia et al. [32] studied the inventory management in a multi-channel distribution system where the Stackelberg and Nash game were employed to solve the optimal solutions. They found that in case the total prices and the production cost were equal, a more capacious inventory was carried by the manufacturer in the simultaneous game. Then, Chern et al. [33] proposed vendor-buyer supply chain models and derived the optimal solutions under noncooperative Nash equilibrium. Tsao et al. [34] developed a model to optimize the retail shelf-space and introduced an RS game in a supply chain. Recently, Wu et al. [35] developed a supply chain model where the demand was associated with the default risk under a supplier-Stackelberg model and proposed two inventory models: (i) centralized decision and (ii) decentralized decision. Chua et al. [36] proposed a Make To Order (MTO) supply chain to analyze the production planning problem through the Stackelberg game. Based on the assumption that the market demand depended on the displayed stock, Jaggi et al. [37] obtained the optimal solutions under three decision circumstances, i.e., centralized, supplier dominated Stackelberg, and Nash equilibrium solutions. Nazari et al. [38] studied the optimal ordering and pricing policies using game theory in the closed-loop supply chain. Two types of game strategies, i.e., Nash and Stackelberg game, 
Table 1. Summary of the related literature.

\begin{tabular}{lccccccc}
\hline Authors & Year & i & ii & iii & iv & v & vi \\
\hline Teng et al. [13] & 2012 & $\sqrt{ }$ & $\times$ & $\times$ & $\times$ & $\sqrt{ }$ & $\times$ \\
Chern et al. [31] & 2013 & $\sqrt{ }$ & $\sqrt{ }$ & $\sqrt{ }$ & $\times$ & $\sqrt{ }$ & $\times$ \\
Hoseininia et al. [32] & 2013 & $\sqrt{ }$ & $\sqrt{ }$ & $\sqrt{ }$ & $\times$ & $\times$ & $\times$ \\
Tsao et al. [34] & 2014 & $\sqrt{ }$ & $\sqrt{ }$ & $\times$ & $\sqrt{ }$ & $\sqrt{ }$ & $\times$ \\
Xiao et al. [41] & 2014 & $\sqrt{ }$ & $\sqrt{ }$ & $\times$ & $\sqrt{ }$ & $\times$ & $\sqrt{ }$ \\
Jaggi et al. [20] & 2015 & $\sqrt{ }$ & $\times$ & $\times$ & $\times$ & $\sqrt{ }$ & $\times$ \\
Pal et al. [39] & 2015 & $\sqrt{ }$ & $\sqrt{ }$ & $\sqrt{ }$ & $\sqrt{ }$ & $\times$ & $\times$ \\
Yang and Birge [42] & 2016 & $\sqrt{ }$ & $\times$ & $\times$ & $\times$ & $\sqrt{ }$ & $\times$ \\
Peura et al. [24] & 2017 & $\times$ & $\sqrt{ }$ & $\times$ & $\times$ & $\sqrt{ }$ & $\times$ \\
Wu et al. [35] & 2017 & $\sqrt{ }$ & $\sqrt{ }$ & $\sqrt{ }$ & $\times$ & $\sqrt{ }$ & $\sqrt{ }$ \\
Lee et al. [43] & 2018 & $\sqrt{ }$ & $\sqrt{ }$ & $\times$ & $\times$ & $\sqrt{ }$ & $\times$ \\
Nazari et al. [38] & 2018 & $\sqrt{ }$ & $\sqrt{ }$ & $\sqrt{ }$ & $\sqrt{ }$ & $\times$ & $\times$ \\
Jaggi et al. [37] & 2018 & $\sqrt{ }$ & $\sqrt{ }$ & $\sqrt{ }$ & $\times$ & $\times$ & $\sqrt{ }$ \\
Feng et al. [29] & 2019 & $\sqrt{ }$ & $\sqrt{ }$ & $\times$ & $\times$ & $\sqrt{ }$ & $\sqrt{ }$ \\
\hline This paper & & $\sqrt{ }$ & $\sqrt{ }$ & $\sqrt{ }$ & $\sqrt{ }$ & $\sqrt{ }$ & $\sqrt{ }$ \\
\hline
\end{tabular}

in a decentralized decision were also considered in their study. More related papers can be found in the references of the studies conducted by Pal et al. [39] and Wang et al. [40]. However, these studies did not compare the results in both a centralized decision and Stackelberg game under decentralized decision in detail.

Based on the trade credit policy, while some of the abovementioned studies considered only the supplier profit or retailer profit models, some others either considered decentralized decision without considering centralized decision or developed only one supply chain member within a Stackelberg model structure. For example, Chern et al. [31] considered only the SS model without mentioning the RS model. However, a model that could simultaneously consider both centralized decision with trade credit and two Stackelberg structures in a decentralized decision has not yet been developed.

The three main contributions of the present study include: a) comparison of the supplier's and retailer's profits under different decision circumstances, i.e., supplier dominated, retailer dominated, and centralized decision (much of the previous literature is focused only on the profit of individual supply chain member); b) study of a supplier-retailer replenishment model under both centralized and decentralized decisions (other scholars studied the decentralized decision only without considering the centralized decision; hence, an incomplete and not specific study); and c) use of MATLAB software for example analysis, thus leading to conclusions that have not been obtained before. For instance, the researchers found that under the condition of a credit period, SS model was more beneficial to the supply chain than retailer-Stackelberg model. However, in the absence of credit period, the result was opposite.

A summary of the related literature and its contrast to our research is given in Table 1 , considering the following factors: (i) the retailer's profit or cost, (ii) the supplier's profit or cost, (iii) SS model, (iv) RS model, (v) trade credit, and (vi) centralized decision.

\section{Notation and assumptions}

Table 2 lists the notations used in this paper.

\section{Assumptions}

Following the industrial practices and our incentives to develop this study, five assumptions are made in the model:

1. Replenishment rate is instantaneous;

2 . In the context of increasingly fierce market competition, we assume that shortages are not allowed;

3. Time horizon is infinite;

4. Trade credit as an important financial resource is considered by retailers as a tool for price reduction. 
Table 2. Notations.

\begin{tabular}{ll}
\hline$M$ & The retailer's trade credit period offered by supplier in years, decision variable \\
$T$ & The retailer's replenishment cycle time in years, decision variable \\
$Q$ & The retailer's order quantity in units \\
$D$ & Annual demand rate for the item \\
$C$ & Supplier's unit production cost \\
$V$ & The wholesale price charged by the supplier \\
$P$ & The retail price of products charged by the retailer \\
$I_{e}$ & Interest that can be earned per unit time \\
$I_{c}$ & Interest payable per unit time \\
$I_{s}$ & Supplier's capital opportunity cost \\
$h$ & The unit holding cost per year excluding interest charge \\
$A_{r}$ & The retailer's ordering cost \\
$A_{s}$ & The supplier's ordering cost \\
$T P_{i}^{j}$ & The $i$ 's annual total profit, $i=s, r, s c$ and $j=s s, r s, c$ \\
& \\
$S u p e r s c r i p t$ & \\
$s s$ & Supplier Stackelberg model \\
$r s$ & Retailer Stackelberg model \\
$c$ & Centralized supply chain structure \\
$*$ & The optimal solution \\
$S C$ &
\end{tabular}

According to Jaggi et al. [44], trade credit period offered by sellers to retailers has a positive impact on the demand for goods. In this regard, for simplicity, we assume that the relationship between the demand rate $D$ and supplier's trade credit period $M$ is given by $D=k e^{\alpha M}$, where $k$ and $\alpha$ are positive constants;

5. As stated by Abad and Jaggi [45], the supplier opportunity cost of capital is an incremental linear function of $M, I_{s}=a+b M, a>0, b>0$. In other words, the credit period offered by the supplier enhances the supplier's risk. The values of $a$ and $b$ can be determined by the relationship between interest rate and loan term as well as specific factors. In addition, it has been assumed that the supplier follows a lot-for-lot strategy. Therefore, the supplier does not need to pay the holding cost related to the order quantity $Q$.

\section{Model formulation}

This section formulates the profit models for the retailer and supplier under different situations, i.e., $M \leq T$ and $M \geq T$. In addition, since the interest earned, interest payable, and inventory depletion vary in different circumstances, two charts are depicted in order to formulate the profit functions.

\subsection{The retailer's problem}

The retailer intends to obtain its optimal cycle time $T$ to maximize the total profit and the retailer determines it under the two following conditions: (1) $M \leq T$ or (2) $M \geq T$.

\section{Case 1. $M \leq T$}

As observed in Figure 1, the retailer's interest charged per year is calculated by $V I_{c} D(T-M)^{2} / 2 T$, and the interest earned is calculated via $P I_{e} D M^{2} / 2 T$. Figure 2(a) shows the inventory level at the interval $[M, T]$. Hence, the retailer's profit can be expressed as follows:

$$
\begin{aligned}
T P_{r}{ }^{(1)}(T)= & (P-V) D-\frac{A_{r}}{T}-\frac{h D T}{2}+\frac{P I_{e} D M^{2}}{2 T} \\
& -\frac{V I_{c} D(T-M)^{2}}{2 T} .
\end{aligned}
$$

The first term in Eq. (1) denotes the retailer's sales revenue. The second and third terms represent 


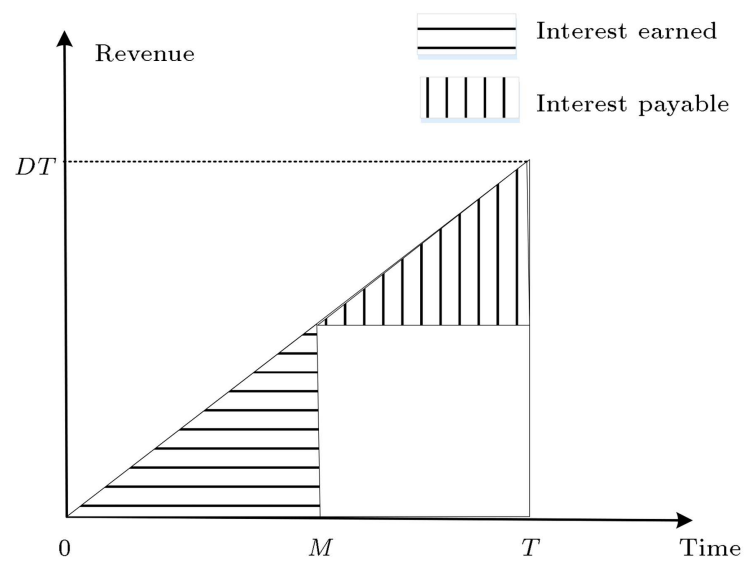

Figure 1. Total amount of interest earned and interest payable when $M \leq T$.

the retailer's ordering cost per cycle and holding cost, respectively. The fourth term in Eq. (1) stands for the retailer's interest earned, and the last one is the interest payable at the interval $[M, T]$.

\section{Case 2. $M \geq T$}

In this case, the account is settled at $T=M$ and the retailer does not need to pay any interest charge. Figure 2 (b) presents the inventory level during the interval $[T, M]$. According to Figure 3, the retail's interest earned is $P I_{e} D(2 M-T) / 2$. Hence, the retailer's profit can be expressed as follows:

$$
\begin{aligned}
T P_{r}{ }^{(2)}(T)= & (P-V) D-\frac{A_{r}}{T}-\frac{h D T}{2} \\
& +\frac{P I_{e} D(2 M-T)}{2} .
\end{aligned}
$$

Similar to the interpretation of Eq. (1), the first three terms in Eq. (2) represent the retailer's sales revenue, ordering cost, and holding cost, respectively. Since the retailer has no interest payable at the interval $[T, M]$, the last term in Eq. (2) denotes the interest earned.

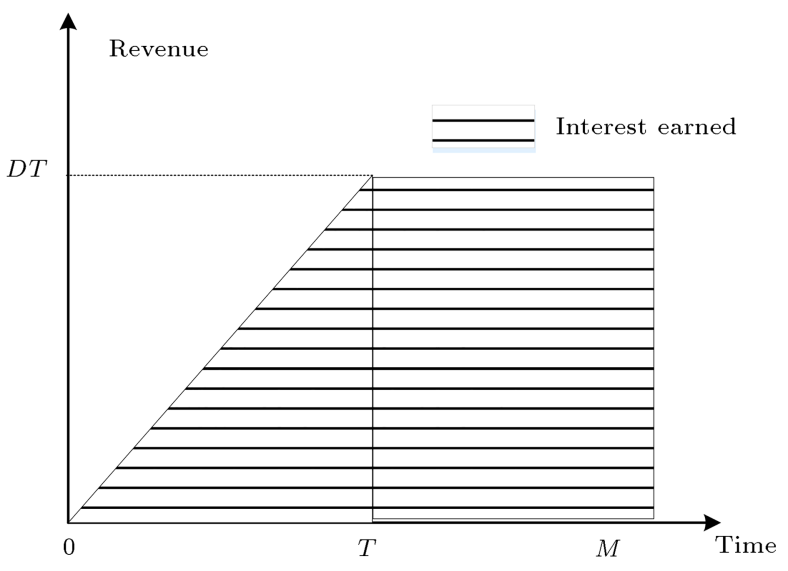

Figure 3. Total amount of interest earned when $M \geq T$.

\subsection{The supplier's problem}

According to Assumption 5, the supplier does not need to pay any holding cost. Hence, the supplier's annual profit total profit is calculated as follows:

$$
T P_{s}(M)=(V-C) D-\frac{A_{s}}{T}-(a+b M) D V M .
$$

The first and second terms in Eq. (3) represent the supplier's sales revenue and the supplier's ordering cost, respectively. According to Assumption 5, we know that the supplier's opportunity cost is $I_{s}=a+b M$. Hence, the last term in Eq. (3) means the supplier's total opportunity cost.

\section{Equilibrium decisions under different structures}

In this section, three models, namely the SS, RS, and centralized supply chain $(c)$, are discussed.

\subsection{Supplier Stackelberg (SS) model}

\subsubsection{The retailer's decision}

Under the assumptions of SS, first, the retailer's reaction function is derived while choosing the mentioned strategy. Then, the supplier determines $M$ to maximize

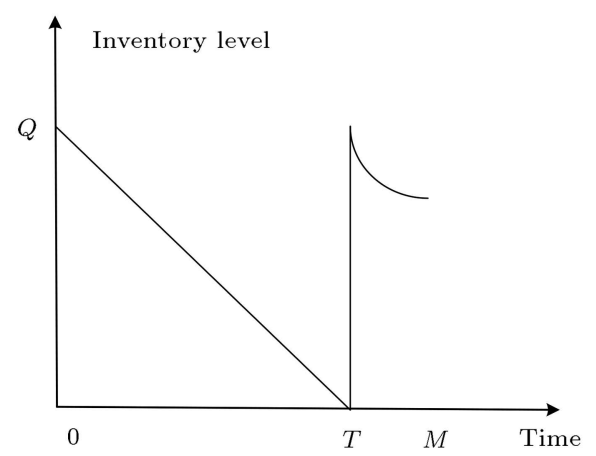

(b)

nd $M \geq T$.

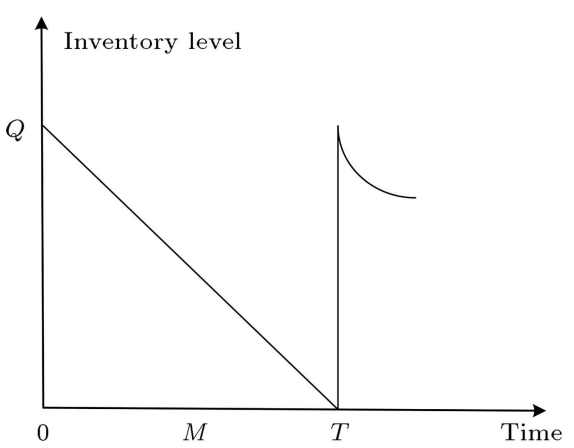

(a) 
its profit by taking the retailer's reaction into consideration. This section refers to the study conducted by Chern et al. [31] (2013).

Case 1. $M \leq T$. To maximize the retailer's profit, the first and second derivatives of Eq. (1) with respect to $T$ should be calculated and then, the optimal replenishment cycle time is given by:

$$
T^{*}=\sqrt{\frac{2 A_{r}-D M^{2}\left(P I_{e}-V I_{c}\right)}{h D+V I_{c} D}} .
$$

Proof: See the Appendix.

Case 2. $M \geq T$. The optimal replenishment cycle time is calculated by:

$$
T^{*}=\sqrt{\frac{2 A_{r}}{h D+P I_{e} D}} .
$$

Proof: See the Appendix.

Theorem 1. Let $\Delta_{1}=2 A_{r}-D M^{2}\left(P I_{e}+h\right)$, for any given $M$, then:

(a) If $\Delta_{1}>0$, the optimal replenishment period is $T^{*}>M$, as shown in Eq. (4);

(b) If $\Delta_{1}<0$, the optimal replenishment period is $T^{*}<M$, as shown in Eq. (5);

(c) If $\Delta_{1}=0$, the optimal replenishment period is $T^{*}=M$.

Proof: See the Appendix.

The economic interpretation of Theorem 1 is similar to the results obtained by Chern et al. [31].

\subsubsection{The supplier's decision}

Case 1. $M \leq T$. After substituting Eq. (4) into Eq. (3), the supplier's profit can be calculated as:

$$
\begin{aligned}
T P_{s}^{(1)}= & k e^{\alpha M}[V-C-(a+b M) V M] \\
& -A_{s} \sqrt{\frac{\left(h+V I_{c}\right) k e^{\alpha M}}{2 A_{r}-k e^{\alpha M} M^{2}\left(P I_{e}-V I_{c}\right)}} .
\end{aligned}
$$

The optimal trade credit period is given by:

$$
M^{*}=0 \text {. }
$$

Proof: See the Appendix.

In case supplier does not offer the trade credit, its profit can reach its maximum. In such a case, the demand rate is $D^{*}=k$ and the supplier's opportunity cost is $I_{s}=a$. Therefore, the profits of the supplier and the retailer are measured by:

$$
T P_{r}^{s s *}=(P-V) k-\sqrt{2 A_{r} k\left(h+V I_{c}\right)},
$$

$$
T P_{s}^{s s *}=(V-C) k-A_{s} \sqrt{\frac{\left(h+V I_{c}\right) k}{2 A_{r}}} .
$$

Case 2. $M \geq T$. By substituting Eq. (5) into Eq. (3), the supplier's profit can be measured as shown in the following:

$$
\begin{gathered}
T P_{s}^{(2)}=k e^{\alpha M}[V-C-(a+b M) V M] \\
-A_{s} \sqrt{\frac{\left(h+P I_{e}\right) k e^{\alpha M}}{2 A_{r}}} .
\end{gathered}
$$

Similar to Case 1, it can be concluded that $T P_{s}^{(2)}$ is a decreasing function with respect to $M$ when $M \geq$ $T$. Therefore, maximization of $T P_{s}^{(2)}$ over the interval $[T,+\infty)$ is $T P_{s}(M=T)$, and the optimal trade credit is given by:

$$
M^{*}=\sqrt{\frac{2 A_{r}}{\left(h+P I_{e}\right) k e^{\alpha M}}} .
$$

Proof: See the Appendix.

In other words, in case the trade credit offered by the supplier is equal to the retailer's replenishment cycle time, the supplier's profit reaches its maximum and the demand rate becomes $D^{*}=k e^{\alpha \sqrt{2 A_{r} /\left(h+P I_{e}\right) k e^{\alpha M}}}$; therefore, the supplier's and the retailer's profits are calculated as shown in the following:

$$
\begin{aligned}
& T P_{r}^{s s *}=(P-V) k e^{\alpha \sqrt{2 A_{r} /\left(h+P I_{e}\right) k e^{\alpha M}}} \\
& -\sqrt{\frac{k e^{\alpha \sqrt{2 A_{r} /\left(h+P I_{e}\right) k e^{\alpha M}}} A_{r}\left(h+P I_{e}\right)}{2}} \\
& +\frac{\left(P I_{e}-h\right) k e^{\alpha \sqrt{2 A_{r} /\left(h+P I_{e}\right) k e^{\alpha M}}}}{2} \\
& \sqrt{\frac{2 A_{r}}{\left(h+P I_{e}\right) k e^{\alpha \sqrt{2 A_{r} /\left(h+P I_{e}\right) k e^{\alpha M}}}}} \\
& T P_{s}^{s s *}=k e^{\alpha \sqrt{2 A_{r} /\left(h+P I_{e}\right) k e^{\alpha M}}} \\
& {\left[V-C-V\left(a \sqrt{\frac{2 A_{r}}{\left(h+P I_{e}\right) k e^{\alpha \sqrt{2 A_{r} /\left(h+P I_{e}\right) k e^{\alpha M}}}}}\right.\right.} \\
& \left.\left.+\frac{2 b A_{r}}{\left(h+P I_{e}\right) k e^{\alpha \sqrt{2 A_{r} /\left(h+P I_{e}\right) k e^{\alpha M}}}}\right)\right] \\
& -A_{s} \sqrt{\frac{\left(h+P I_{e}\right) k e^{\alpha \sqrt{2 A_{r} /\left(h+P I_{e}\right) k e^{\alpha M}}}}{2 A_{r}}} .
\end{aligned}
$$

Corollary 1. If $P I_{e}>V I_{c}$ :

1. The higher the value of $A_{r}$, the higher the value 
of $\Delta_{1}, T^{*}$, and $T P_{s}^{r s^{*}}$ and the lower the value of $T P_{r}^{r s^{*}}$

2. Higher values of $k, \alpha, M$, and $h$ make the values of $\Delta_{1}$ and $T^{*}$ lower.

Based on Theorem 1 and Corollary 1, it can be concluded that first, when $\Delta_{1}>0$, as expressed in Case 1, the optimal solution is $T^{*}>M^{*}$, and vice versa. To be specific, if $\Delta_{1}=0$, the optimal replenishment cycle time degenerates into the trade credit period. The second insight is that if $P I_{e}>$ $V I_{c}$, the value of $\Delta_{1}$ increases with a higher value of retailer's ordering cost and a lower value of demand rate, implying that under SS model, the lower the demand rate and the higher the retailer's ordering cost, the lower the replenishment cycle time.

Furthermore, some managerial insights can be obtained as expressed in the following. In the case of $M<T$, the supplier's profit will reach its maximum only when the supplier does not offer the trade credit period. In the case of $M \geq T$, if the trade credit period offered is equal to the retailer's replenishment cycle time, the supplier can get optimal profit. In other words, from the supplier's perspective, it is better for the supplier not to provide the trade credit period or the trade credit period offered is less than the replenishment cycle time.

\subsection{Retailer Stackelberg (RS) model}

In the RS model, the supplier's reaction function is deduced. Then, the retailer considers the supplier's response to determine $T$ by maximizing its own profit.

\subsubsection{Supplier's decision}

To maximize the supplier's profit, by taking the first and second derivatives of Eq. (3) with respect to $M$, we obtain by Eq. (14) as shown in Box I.

Proof. See the Appendix.

\subsubsection{Retailer's decision}

Case 1. $M \leq T$. By substituting Eq. (13) into Eq. (1), the retailer's profit can be obtained as follows:

$$
\begin{aligned}
& T P_{r}^{(1)}(T)=(P-V) k e^{\alpha M^{*}}-\frac{A_{r}}{T} \\
& -\frac{k e^{\alpha M^{*}} T\left(h+V I_{c}\right)}{2}+\frac{k e^{\alpha M^{*}} M^{*^{2}}\left(P I_{e}-V I_{c}\right)}{2 T} \\
& +V I_{c} k e^{\alpha M^{*}} M^{*^{2}}
\end{aligned}
$$

After calculation, the optimal trade credit period is given by:

$$
T^{*}=\sqrt{\frac{2 A_{r}-\left(P I_{e}-V I_{c}\right) k e^{\alpha M^{*}} M^{*^{2}}}{\left(h+V I_{c}\right) k e^{\alpha M^{*}}}} .
$$

Proof. See the Appendix.

Hence, the optimal profit of the supplier and retailer would be:

$$
\begin{aligned}
& T P_{r}^{r s *}=(P-V) k e^{\alpha M^{*}} \\
& -\frac{A_{r} \sqrt{\left(h+V I_{c}\right) k e^{\alpha M^{*}}}}{\sqrt{2 A_{r}-k e^{\alpha M^{*}} M^{*^{2}}\left(P I_{e}-V I_{c}\right)}} \\
& -\frac{k e^{\alpha M^{*}}\left(h+V I_{c}\right) \sqrt{2 A_{r}-k e^{\alpha M^{*}} M^{*^{2}}\left(P I_{e}-V I_{c}\right)}}{2 \sqrt{\left(h+V I_{c}\right) k e^{\alpha M}}} \\
& +\frac{k e^{a M^{*}} M^{*^{2}}\left(P I_{e}-V I_{c}\right) \sqrt{\left(h+V I_{c}\right) k e^{a M^{*}}}}{2 \sqrt{2 A_{r}-k e^{\alpha M^{*}} M^{*^{2}}\left(P I_{e}-V I_{c}\right)}} \\
& +V I_{c} k e^{a M^{*}} M^{*} \\
& T P_{s}^{r s *}=k e^{a M^{*}}\left[V-C-\left(a+b M^{*}\right) V M^{*}\right] \\
& -\frac{A_{s} \sqrt{\left(h+V I_{c}\right)}}{\sqrt{2 A_{r}-k e^{a M^{*}} M^{*^{2}}\left(P I_{e}-V I_{c}\right)}} .
\end{aligned}
$$

Case 2. $M \geq T$. After substituting Eq. (14) into Eq. (2), we find:

$$
\begin{aligned}
T P_{r}^{(2)}= & (P-V) k e^{\alpha M^{*}}-\frac{A_{r}}{T}-\frac{h T k e^{\alpha M^{*}}}{2} \\
& +P I_{e} k e^{\alpha M^{*}} \frac{2 M^{*}-T}{2} .
\end{aligned}
$$

After calculation, we can get:

$$
T^{*}=\sqrt{\frac{2 A_{r}}{\left(h+P I_{e}\right) k e^{\alpha M^{*}}}} .
$$

Proof. See the Appendix.

Then, the profit of the supplier and the retailer can be obtained by:

$$
M^{*}=\frac{-(\alpha a V+2 b V)+\sqrt{(\alpha a V+2 b V)^{2}-4 \alpha b V(a V-\alpha V+\alpha C)}}{2 \alpha b V} .
$$




$$
\begin{aligned}
T P_{r}^{r s *}= & (P-V) k e^{a M^{*}}-\frac{\sqrt{A_{r} k e^{a M^{*}}\left(h+P I_{e}\right)}}{2} \\
- & \frac{h k e^{a M^{*}}}{2} \sqrt{\frac{2 A_{r}}{\left(h+P I_{e}\right) k e^{a M^{*}}}} \\
+ & \frac{P I_{e} k e^{a M^{*}}}{2}\left(2 M^{*}-\sqrt{\frac{2 A_{r}}{\left(h+P I_{e}\right) k e^{a M^{*}}}}\right) \\
T P_{s}^{r s *}= & k e^{a M^{*}}\left[V-C-\left(a+b M^{*}\right) V M^{*}\right] \\
& -A_{s} \sqrt{\frac{\left(h+P I_{e}\right) k e^{a M^{*}}}{2 A_{r}}} .
\end{aligned}
$$

Theorem 2. Let $\Delta_{2}=2 A_{r}-k e^{\alpha M^{*}} M^{*^{2}}\left(P I_{e}+h\right)$, for any given $T$; then, we obtain:

(a) If $\Delta_{2}>0$, the optimal replenishment period is $T^{*}>M^{*}$, as shown in Eq. (16);

(b) If $\Delta_{2}<0$, the optimal replenishment period is $T^{*}<M^{*}$, as shown in Eq. (20);

(c) If $\Delta_{2}=0$, the optimal replenishment period is $T^{*}=M^{*}$.

Proof. See the Appendix.

The economic interpretation of Theorem 2 is given in the following. The benefit the retailer receives from the trade credit period is $D M^{2} P I_{e} / 2$; thus, the true ordering cost is $\left(A_{r}-D M^{2} P I_{e} / 2\right)$ and the inventory cost is $D M^{2} h / 2$. In this regard, if the ordering cost is higher than the inventory $\operatorname{cost}\left(\Delta_{2}>0\right)$, it can be concluded that the optimal replenishment period $T^{*}$ is higher than the trade credit period $M$, as shown in Eq. (16), and vice versa. If the condition $2 A_{r}-$ $D M^{2}\left(P I_{e}-V I_{c}\right)>0$ is false, then we can get:

$$
\begin{gathered}
\Delta_{2}=2 A_{r}-D M^{2}\left(P I_{e}+h\right)<D M^{2}\left(P I_{e}-V I_{c}\right) \\
-D M^{2}\left(P I_{e}+h\right)=-D M^{2}\left(h+V I_{c}\right)<0
\end{gathered}
$$

Therefore, if $2 A_{r}-D M^{2}\left(P I_{e}-V I_{c}\right)<0$, the optimal replenishment period is given in Eq. (20). Since the wholesale price $V$ is lower than the retailer's selling price $V$, we can assume $P I_{e}>V I_{c}$, thus obtaining the following results:

Corollary 2. If $P I_{e}>V I_{c}$, we have:

1. The higher the value of $A_{r}$, the higher the value of $\Delta_{2}, T^{*}, T P_{s}^{r s^{*}}$ and the lower the value of $T P_{r}^{\mathrm{RS}^{*}}$;

2. Higher values of $k, \alpha, M$, and $h$ would make the values of $\Delta_{2}$ and $T^{*}$ lower.

Based on Theorem 2 and Corollary 2, similar conclusions to the ones in the previous subsection can be drawn.

In addition, the following managerial insights would be obtained: First, the trade credit period is not relevant to the retailer's replenishment cycle time under RS model and is determined by the production cost, wholesale price, demand rate, and the opportunity cost. In other words, under RS, the supplier does not change the size of the trade credit period no matter how long the replenishment cycle time offered by the retailer is. Second, in case the holding cost decreases and the trade credit period offered increases, the replenishment cycle time and demand rate will be greater. Therefore, the profit of the supplier and retailer will increase and the whole supply chain will be optimized.

\subsection{Centralized decision}

In the centralized decision, the supplier and the retailer cooperate as one decision-maker. That is to say, they decide on the replenishment plan together to maximize their whole expected profits.

Case 1. $M \leq T$. Through combing Eqs. (1) and (3), the total profit of the whole supply chain will be:

$$
\begin{aligned}
T P_{s c}= & k e^{\alpha M}(P-C)-\frac{A_{r}+A_{s}}{T} \\
& -\frac{k e^{\alpha M} T\left(h+V I_{c}\right)}{2} \\
& +\frac{k e^{\alpha M} M^{2}\left(P I_{e}-V I_{c}\right)}{2 T}+k e^{\alpha M} \\
& V M\left[I_{c}-(a+b M)\right] .
\end{aligned}
$$

After calculation, the optimal solution that maximizes the centralized supply chain profit is achieved by:

$$
T^{*}=\sqrt{\frac{2\left(A_{r}+A_{s}\right)-k e^{\alpha M} M^{2}\left(P I_{e}-V I_{c}\right)}{k e^{\alpha M}\left(h+V I_{c}\right)}},
$$

Eq. (25) is shown in Box II.

Proof. See the Appendix.

Besides, the optimal profit for the centralized supply chain will be:

$$
\begin{aligned}
T P_{s c}^{c *}= & k e^{\alpha M^{*}}(P-C)-\left(A_{r}+A_{s}\right) \\
& \sqrt{\frac{k e^{\alpha M}\left(h+V I_{c}\right)}{2\left(A_{r}+A_{s}\right)-k e^{\alpha M} M^{2}\left(P I_{e}-V I_{c}\right)}} \\
& -\frac{k e^{\alpha M^{*}}\left(h+V I_{c}\right)}{2} \\
& \sqrt{\frac{2\left(A_{r}+A_{s}\right)-k e^{\alpha M} M^{2}\left(P I_{e}-V I_{c}\right)}{k e^{\alpha M}\left(h+V I_{c}\right)}}
\end{aligned}
$$




$$
\begin{aligned}
& M^{*}=\frac{-2\left[\left(P I_{e}-V I_{c}\right)+\left(I_{c}-a\right) \alpha V T-2 b V T\right]}{2 \alpha\left(P I_{e}-V I_{c}-2 b V T\right)} \\
& +\frac{\sqrt{4\left[\left(P I_{e}-V I_{c}\right)+\left(I_{c}-a\right) \alpha V T-2 b V T\right]^{2}-8 \alpha\left(P I_{e}-V I_{c}-2 b V T\right)\left[2 T V\left(I_{c}-a\right)+\alpha T\left(2 P-2 C-h T-V I_{c} T\right)\right]}}{2 \alpha\left(P I_{e}-V I_{c}-2 b V T\right)} .
\end{aligned}
$$

\section{Box II}

$$
\begin{aligned}
& +\frac{k e^{\alpha M^{*}} M^{*^{2}}\left(P I_{e}-V I_{c}\right)}{2} \\
& \sqrt{\frac{k e^{\alpha M}\left(h+V I_{c}\right)}{2\left(A_{r}+A_{s}\right)-k e^{\alpha M} M^{2}\left(P I_{e}-V I_{c}\right)}} \\
& +k e^{\alpha M^{*}} V M^{*}\left[I_{c}-\left(a+b M^{*}\right)\right] .
\end{aligned}
$$

In order to prove that $T P_{s c}$ is concave in $T$ and $M$, it is sufficient to show that $\partial^{2} T P_{s c} / \partial T^{2}<0$, $\partial^{2} T P_{s c} / \partial M^{2}<0$, and $|H| \geq 0$, where $H$ is the Hessian matrix of $T P_{s c}$. Then, we set:

$$
\begin{aligned}
& W_{1}= \frac{k e^{\alpha M} M^{2}\left(P I_{e}-V I_{c}\right)-2\left(A_{r}+A_{s}\right)}{T^{3}} \\
& \times k e^{\alpha M}\left\{\alpha^{2}\left[P-C-\frac{T\left(h+V I_{c}\right)}{2}\right]\right. \\
&+\frac{\left(P I_{e}-V I_{c}\right)\left(\alpha^{2} M^{2}+4 \alpha M+2\right)}{2 T} \\
&+\left(I_{c}-a-b M\right)\left(\alpha^{2} V M+2 \alpha V\right) \\
&-2 \alpha b V M-2 b V\} \\
& W_{2}= \\
&-\left\{k e^{\alpha M}\left[\frac{\alpha\left(h+V I_{c}\right)}{2}+\frac{\left(\alpha M^{2}+2 M\right)\left(P I_{e}-V I_{c}\right)}{2 T^{2}}\right]\right\}^{2} .
\end{aligned}
$$

Theorem 3. If $W_{1}+W_{2} \geq 0, T P_{s c}$ is a concave function in $M$ and $T$.

Proof. See the Appendix.
Case 2. $\quad M \geq T$. By combining Eqs. (2) and (3), the profit of the whole supply chain is calculated as:

$$
\begin{aligned}
T P_{s c} & =k e^{\alpha M}(P-C)-\frac{A_{r}+A_{s}}{T}-\frac{k e^{\alpha M} T h}{2} \\
& +\frac{k e^{\alpha M} P I_{e}(2 M-T)}{2}-k e^{\alpha M} V M(a+b M) .
\end{aligned}
$$

Then, the optimal solutions that maximize the centralized supply chain profit are achieved by:

$$
T^{*}=\sqrt{\frac{2\left(A_{r}+A_{s}\right)}{k e^{\alpha M}\left(h+P I_{e}\right)}}
$$

Eq. (29) is shown in Box III.

Proof. See the Appendix

The optimal profit for the centralized supply chain is formulated as follows:

$$
\begin{aligned}
& T P_{s c}^{c *}=k e^{\alpha M^{*}}(P-C)-\left(A_{r}+A_{s}\right) \\
& \quad \sqrt{\frac{k e^{\alpha M}\left(h+P I_{e}\right)}{2\left(A_{r}+A_{s}\right)}}-\frac{k e^{\alpha M} h}{2} \\
& \sqrt{\frac{2\left(A_{r}+A_{s}\right)}{k e^{\alpha M}\left(h+P I_{e}\right)}}+k e^{\alpha M^{*}} P I_{e}\left(M^{*}\right. \\
& \left.-\sqrt{\frac{A_{r}+A_{s}}{2 k e^{\alpha M}\left(h+P I_{e}\right)}}\right)-k e^{\alpha M^{*}} V M^{*}\left(a+b M^{*}\right) .
\end{aligned}
$$

In order to prove that $T P_{s c}$ is concave in $T$ and $M$, it is sufficient to show that $\partial^{2} T P_{s c} / \partial T^{2}<0$,

$$
\begin{aligned}
M^{*} & =\frac{2 \alpha P I_{e}-2 \alpha a V-4 b V}{4 \alpha b V} \\
& +\frac{\sqrt{4\left(\alpha P I_{e}-\alpha a V-2 b V\right)^{2}-16 \alpha b V\left[P I_{e} T \alpha-2 P I_{e}+2 a V-\alpha(2 P-2 C-T h)\right]}}{4 \alpha b V} .
\end{aligned}
$$


$\partial^{2} T P_{s c} / \partial M^{2}<0$ and $|H| \geq 0$, where $H$ is the Hessian matrix of $T P_{s c}$. Then, we set:

$$
\begin{aligned}
W_{3}= & -\frac{2\left(A_{r}+A_{s}\right)}{T^{3}} \times \alpha k e^{\alpha M}\left[\alpha\left(P-C-\frac{T h}{2}\right)\right. \\
& +\frac{\alpha P I_{e}(2 M-T)}{2}-\alpha V M(a+b M)+2 P I_{e} \\
& -2 V(a+2 b M)]-2 k e^{a M} b V, \\
W_{4}= & -\left[\frac{\alpha k e^{\alpha M}\left(h+P I_{e}\right)}{2}\right]^{2} .
\end{aligned}
$$

Theorem 4. If $W_{3}+W_{4} \geq 0, T P_{s c}$ is a concave function in $M$ and $T$.

\section{Proof. See the Appendix.}

The optimal decisions under different decision circumstances were derived, as explained in Sections 5.1-5.3. In Section 6, the difference between the optimal solutions under three supply chain models is discussed in detail and the effects of changes in some parameters on the performance of the supply chain are examined.

\section{Numerical example and analysis}

In this section, some numerical examples are provided to clarify the above theoretical results and gain some insights into managerial areas.

Example 1. Let $A_{s}=\$ 50 /$ order, $A_{r}=\$ 100 /$ order, $P=\$ 3.0 /$ unit, $V=\$ 2.50 /$ unit, $C=\$ 1 /$ unit, $h=$ $\$ 1 /$ unit $/$ year, $I_{e}=0.05 /$ year, $I_{c}=0.05 /$ year, $\alpha=2$, $k=1000$, and $I_{s}=0.6+0.5 M$.

In the SS model, for the case of $M<T$, the optimal solution that maximizes Eq. (6) is $M^{*}=0$. Then, according to Eq. (6), the optimal supplier's profit is $T P_{s}^{*}=1381.4$. In addition, in the case of $M \geq T$, the optimal solution maximizing Eq. (10) is $M^{*}=0.3068$ and the optimal supplier's profit is calculated by $T P_{s}^{*}=1936.0087$. A comparison of these two cases shows that $M^{s s *}=0.3068$. Therefore, we have $\Delta_{1}=2 A_{r}-D M^{2}\left(P I_{e}-V I_{c}\right)>0$; the optimal replenishment cycle time derived from Theorem 1 is $T^{s s *}=0.3068$, and the optimal profits of supplier and retailer are $T P_{s}^{s s *}=1538.5$ and $T P_{r}^{s s *}=356.7499$, respectively. Hence, the optimal profit of the supply chain under SS is $T P_{s}{ }^{s * *}+T P_{r}^{r s *}=1895.2499$.

In the RS model, the optimal trade credit that maximizes the retailer's profit is $M^{*}=0.2454$. In this respect, we have $2 A_{r}-D M^{* 2}\left(P I_{e}-V I_{c}\right)=198.08>0$, and based on Theorem 2, the optimal replenishment cycle time is $T^{*}>M^{*}$, as shown in Eq. (16). The optimal solutions maximizing Eq. (15) are $M^{r s *}=$ 0.2454 and $T^{r * *}=0.3279$, and the optimal profits of supplier and retailer are $T P_{s}^{r s *}=1573.6$ and $T P_{r}^{r s *}=$ 226.5316 , respectively. Thus, the optimal total profit of the supply chain under $\mathrm{RS}$ is $T P_{s}^{r s *}+T P_{r}^{r s *}=$ 1800.1316 .

By comparing the optimal decision solutions in the two decentralized cases, we find that $M^{s s *}>M^{r s *}$ and $T^{s * *}<T^{r s *}$. To be specific, compared with the RS model, the supplier in the SS model should offer a longer credit period to improve his/her benefits. Similarly, compared with the SS model, the retailer in the RS model should increase the replenishment period to obtain the optimal solution. In addition, the supply chain can earn more profit in SS model than in RS model.

In the Centralized decision, for the case of $M \geq$ $T$, the value of $\left(W_{1}+W_{2}\right)$ is less than zero; hence, $T P_{s c}$ is not concave in $M$ and $T$, implying that the optimal solutions do not exist. In the case of $M \geq T$, the optimal solutions maximizing Eq. (27) are $M^{*}=$ $0.3667, T^{*}=0.3540$, and $W_{3}+W_{4}>0$; therefore, the optimal profit for the centralized decision is $T P_{s c}^{*}=$ 1657.52. In this respect, the optimal decision solutions are $M^{\mathrm{c} *}=0.3667, T^{\mathrm{c} *}=0.3540$, and $T P_{s c}^{*}=1657.52$.

A comparison of the results in both centralized and decentralized decisions revealed that $T P_{s c}^{c *}>$ $T P_{s c}^{s *}>T P_{s c}^{r s *}$. In other words, the supplier and retailer should make joint decisions to improve the performance of the supply chain.

In addition, the value of $M$ under centralized decision was employed to draw an image of market demand changing with the parameters $\alpha$ and $k$ (Figure 4 ). In Figure 4 , both the parameters $\alpha$ and $k$ have positive effects on the market demand, and the demand is more sensitive to the changes in the value of $\alpha$, which means that in the same range of change, the larger the value of $\alpha$, the greater the market demand.

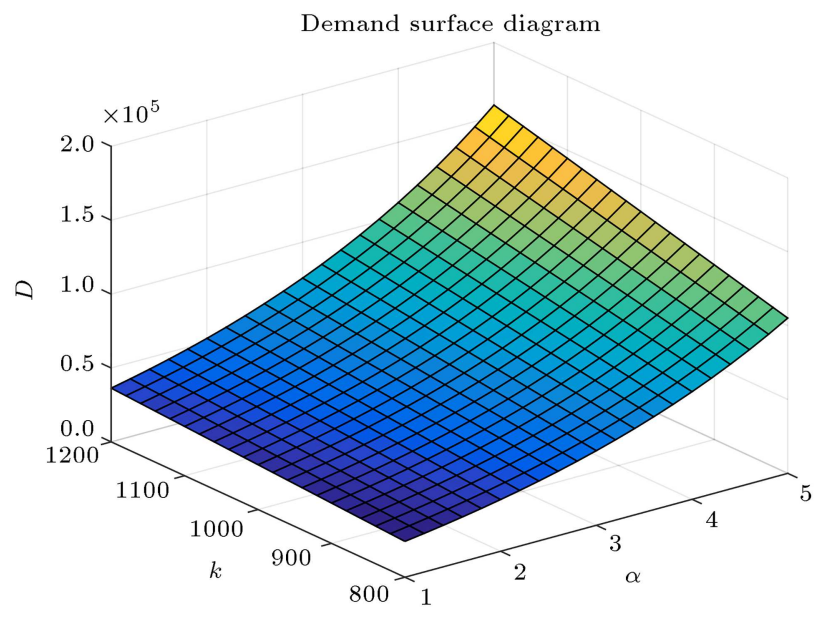

Figure 4. The influence of $\alpha$ and $k$ on the market demand. 


\subsection{Sensitivity analysis}

Example 2. The same data as those given in Example 1 were employed to study the effects of changes in some parameters on the optimal solution and gain the management insights. Based on the results obtained by Ho [46], Chern et al. [31], and other researchers working on this issue, the optimal solutions for different parameters of $A_{s}(30,34,38,42,46,50)$, $A_{r}(90,94,98,102,106,110), P(3,3.4,3.8,4.2,4.6,5), C$ $(0,0.4,0.8,1.2,1.6,2), I_{c}(0,0.04,0.08,0.12,0.16,0.2), I_{e}$ $(0,0.04,0.08,0.12,0.16,0.2)$ were suggested, as shown in Tables 3-6.
The influence of $A_{s}$ and $A_{r}$ on $M, T, T P_{r}$, and $T P_{s}$ is shown in Table 3 , based on which it can be concluded that:

(i) The credit period and replenishment cycle time remain constant as $A_{s}$ increases in both SS model and RS model. However, under centralized decision, the credit period decreases and the replenishment period increases with the increase of $A_{s}$. Additionally, under both SS model and RS model, when the supplier's ordering cost increases, the retailer's profit remains unchanged while the supplier's profit decreases. Thus, it can be seen

Table 3. The impacts of $A_{s}$ and $A_{r}$ on the optimal solutions under different structures.

\begin{tabular}{|c|c|c|c|c|c|c|c|c|c|c|c|}
\hline \multicolumn{2}{|c|}{ Parameter } & \multicolumn{2}{|c|}{ Centralized decision } & \multicolumn{4}{|c|}{ Supplier Stackelberg model } & \multicolumn{4}{|c|}{ Retailer Stackelberg model } \\
\hline & & $M^{*}$ & $T^{*}$ & $M^{*}$ & $T^{*}$ & $T P_{r}^{s s^{*}}$ & $T P_{s}^{s s^{*}}$ & $M^{*}$ & $T^{*}$ & $\boldsymbol{T} \boldsymbol{P}_{r}^{r s^{*}}$ & $T P_{s}^{r s^{*}}$ \\
\hline \multirow{6}{*}{$A_{s}$} & 30 & 0.3709 & 0.3281 & 0.3068 & 0.3068 & 356.7499 & 1604.2 & 0.2454 & 0.3279 & 226.5316 & 1634.6 \\
\hline & 34 & 0.3700 & 0.3334 & 0.3068 & 0.3068 & 356.7499 & 1591.1 & 0.2454 & 0.3279 & 226.5316 & 1622.4 \\
\hline & 38 & 0.3692 & 0.3387 & 0.3068 & 0.3068 & 356.7499 & 1577.9 & 0.2454 & 0.3279 & 226.5316 & 1610.2 \\
\hline & 42 & 0.3683 & 0.3438 & 0.3068 & 0.3068 & 356.7499 & 1564.7 & 0.2454 & 0.3279 & 226.5316 & 1598.0 \\
\hline & 46 & 0.3675 & 0.3489 & 0.3068 & 0.3068 & 356.7499 & 1551.5 & 0.2454 & 0.3279 & 226.5316 & 1585.8 \\
\hline & 50 & 0.3667 & 0.3540 & 0.3068 & 0.3068 & 356.7499 & 1538.5 & 0.2454 & 0.3279 & 226.5316 & 1573.6 \\
\hline \multirow{6}{*}{$A_{r}$} & 90 & 0.3688 & 0.3413 & 0.295 & 0.295 & 370.7344 & 1539.9 & 0.2454 & 0.3108 & 257.8458 & 1565.3 \\
\hline & 94 & 0.3679 & 0.3464 & 0.2995 & 0.2995 & 364.5912 & 1539.5 & 0.2454 & 0.3177 & 245.1186 & 1568.8 \\
\hline & 98 & 0.3671 & 0.3515 & 0.3046 & 0.3046 & 359.6839 & 1539.4 & 0.2454 & 0.3245 & 232.6629 & 1572.1 \\
\hline & 102 & 0.3663 & 0.3565 & 0.3092 & 0.3092 & 354.2033 & 1538.0 & 0.2454 & 0.3312 & 220.4621 & 1575.1 \\
\hline & 106 & 0.3655 & 0.3614 & 0.3136 & 0.3136 & 348.6219 & 1536.1 & 0.2454 & 0.3377 & 208.5011 & 1578.1 \\
\hline & 110 & 0.3647 & 0.3663 & 0.3182 & 0.3182 & 343.5894 & 1534.7 & 0.2454 & 0.3441 & 196.7663 & 1580.8 \\
\hline
\end{tabular}

Table 4. The impacts of $P$ and $C$ on the optimal solutions under different structures.

\begin{tabular}{|c|c|c|c|c|c|c|c|c|c|c|c|}
\hline \multirow{2}{*}{\multicolumn{2}{|c|}{ Parameter }} & \multicolumn{2}{|c|}{ Centralized decision } & \multicolumn{4}{|c|}{ Supplier Stackelberg model } & \multicolumn{4}{|c|}{ Retailer Stackelberg model } \\
\hline & & $M^{*}$ & $T^{*}$ & $M^{*}$ & $T^{*}$ & $T P_{r}^{s s^{*}}$ & $T P_{s}^{s s^{*}}$ & $M^{*}$ & $T^{*}$ & $T P_{r}^{r s^{*}}$ & $\boldsymbol{T} \boldsymbol{P}_{s}^{r s^{*}}$ \\
\hline \multirow{6}{*}{$P$} & 3.0 & 0.3667 & 0.3540 & 0.3068 & 0.3068 & 356.7499 & 1538.3 & 0.2454 & 0.3279 & 226.5316 & 1573.6 \\
\hline & 3.4 & 0.4870 & 0.3111 & 0.3048 & 0.3048 & 1094.9 & 1537.3 & 0.2454 & 0.3262 & 882.9384 & 1572.9 \\
\hline & 3.8 & 0.5715 & 0.2841 & 0.3033 & 0.3033 & 1644.6 & 1536.7 & 0.2454 & 0.3250 & 1375.3 & 1572.3 \\
\hline & 4.2 & 0.7036 & 0.2464 & 0.3009 & 0.3009 & 2553.9 & 1535.2 & 0.2454 & 0.3229 & 2195.8 & 1571.3 \\
\hline & 4.6 & 0.8029 & 0.2213 & 0.2990 & 0.2990 & 3275.0 & 1534.1 & 0.2454 & 0.3213 & 2852.3 & 1570.5 \\
\hline & 5.0 & 0.8974 & 0.1997 & 0.2977 & 0.2977 & 3996.0 & 1532.3 & 0.2454 & 0.3196 & 3508.7 & 1569.7 \\
\hline \multirow{6}{*}{$C$} & 0 & 0.6386 & 0.2697 & 0.3068 & 0.3068 & 356.7499 & 3386.1 & 0.5155 & 0.249 & 815.8342 & 3709.4 \\
\hline & 0.4 & 0.5361 & 0.2988 & 0.3068 & 0.3068 & 356.7499 & 2647.0 & 0.4133 & 0.2759 & 559.3704 & 2713.4 \\
\hline & 0.8 & 0.4256 & 0.3337 & 0.3068 & 0.3068 & 356.7499 & 1907.9 & 0.3036 & 0.3079 & 302.9674 & 1910.4 \\
\hline & 1.2 & 0.3048 & 0.3767 & 0 & 0.4216 & 25.6583 & 1180.1 & 0.1845 & 0.3495 & 160.6272 & 1275.3 \\
\hline & 1.6 & 0.1697 & 0.4310 & 0 & 0.4216 & 25.6583 & 780.104 & 0.0533 & 0.3997 & 56.4009 & 783.25 \\
\hline & 2.0 & 0.0135 & 0.5039 & 0 & 0.4216 & 25.6583 & 380.104 & 0 & 0.4216 & 25.6584 & 381.42 \\
\hline
\end{tabular}


Table 5. The impacts of $V$ and $h$ on the optimal solutions under different structures.

\begin{tabular}{|c|c|c|c|c|c|c|c|c|c|c|c|}
\hline \multirow{2}{*}{\multicolumn{2}{|c|}{ Parameter }} & \multicolumn{2}{|c|}{ Centralized decision } & \multicolumn{4}{|c|}{ Supplier Stackelberg model } & \multicolumn{4}{|c|}{ Retailer Stackelberg model } \\
\hline & & $M^{*}$ & $T^{*}$ & $M^{*}$ & $T^{*}$ & $T P_{r}^{s s^{*}}$ & $T P_{s}^{s s^{*}}$ & $M^{*}$ & $T^{*}$ & $\boldsymbol{T} \boldsymbol{P}_{r}^{r s^{*}}$ & $\boldsymbol{T} \boldsymbol{P}_{s}^{r s^{*}}$ \\
\hline \multirow{6}{*}{$V$} & 1.5 & 0.7254 & 0.2473 & 0.3068 & 0.3068 & 2203.8 & 120.156 & 0.0299 & 0.4186 & 1114.8 & 382.073 \\
\hline & 1.7 & 0.6253 & 0.2733 & 0.3068 & 0.3068 & 1834.4 & 404.182 & 0.0973 & 0.3888 & 1067.8 & 591.435 \\
\hline & 1.9 & 0.5433 & 0.2967 & 0.3068 & 0.3068 & 1465.0 & 688.209 & 0.1479 & 0.3671 & 941.1587 & 819.007 \\
\hline & 2.1 & 0.4748 & 0.3177 & 0.3068 & 0.3068 & 1095.6 & 972.235 & 0.1875 & 0.3507 & 751.0481 & 1060.50 \\
\hline & 2.3 & 0.4167 & 0.3367 & 0.3068 & 0.3068 & 726.1637 & 1256.3 & 0.2193 & 0.3379 & 509.7008 & 1312.70 \\
\hline & 2.5 & 0.3667 & 0.3540 & 0.3068 & 0.3068 & 356.7499 & 1538.5 & 0.2454 & 0.3279 & 226.5316 & 1573.60 \\
\hline \multirow{6}{*}{$h$} & 0 & 0.4039 & 0.9443 & 0.621 & 0.621 & 1731.5 & 218.816 & 0.2454 & 0.9836 & 628.7055 & 1675.3 \\
\hline & 0.4 & 0.3852 & 0.5025 & 0.404 & 0.404 & 760.8910 & 1424.2 & 0.2454 & 0.4799 & 417.4492 & 1621.9 \\
\hline & 0.8 & 0.3722 & 0.3873 & 0.3299 & 0.3299 & 456.6784 & 1529.6 & 0.2454 & 0.3616 & 282.7069 & 1587.8 \\
\hline & 1.2 & 0.3615 & 0.3284 & 0.288 & 0.288 & 273.2611 & 1541.8 & 0.2454 & 0.3021 & 175.1647 & 1560.6 \\
\hline & 1.6 & 0.3520 & 0.2912 & 0.2605 & 0.2605 & 139.9883 & 1532.9 & 0.2454 & 0.2648 & 82.9662 & 1537.3 \\
\hline & 2.0 & 0.3434 & 0.2650 & 0.239 & 0.239 & 31.4529 & 1516.7 & 0.2454 & 0.2386 & 38.7738 & 1516.6 \\
\hline
\end{tabular}

Table 6. The impacts of $I_{c}$ and $I_{e}$ on the optimal solutions under different structures.

\begin{tabular}{|c|c|c|c|c|c|c|c|c|c|c|c|}
\hline \multicolumn{2}{|c|}{ Parameter } & \multicolumn{2}{|c|}{ Centralized decision } & \multicolumn{4}{|c|}{ Supplier Stackelberg model } & \multicolumn{4}{|c|}{ Retailer Stackelberg model } \\
\hline & & $M^{*}$ & $T^{*}$ & $M^{*}$ & $T^{*}$ & $T P_{r}^{s s^{*}}$ & $T P_{s}^{s s^{*}}$ & $M^{*}$ & $T^{*}$ & $\boldsymbol{T} \boldsymbol{P}_{r}^{r s^{*}}$ & $T P_{s}^{r s^{*}}$ \\
\hline \multirow{6}{*}{$I_{c}$} & 0 & 0.3667 & 0.3540 & 0.3068 & 0.3068 & 356.7499 & 1528.3 & 0.2454 & 0.3368 & 266.6554 & 1577.6 \\
\hline & 0.04 & 0.3667 & 0.3540 & 0.3068 & 0.3068 & 356.7499 & 1536.5 & 0.2454 & 0.3295 & 234.5243 & 1574.4 \\
\hline & 0.08 & 0.3667 & 0.3540 & 0.3068 & 0.3068 & 356.7499 & 1543.6 & 0.2454 & 0.3233 & 202.6371 & 1571.5 \\
\hline & 0.12 & 0.3667 & 0.3540 & 0.3068 & 0.3068 & 356.7499 & 1549.8 & 0.2454 & 0.3180 & 170.9487 & 1568.9 \\
\hline & 0.16 & 0.3667 & 0.3540 & 0.3068 & 0.3068 & 356.7499 & 1555.4 & 0.2454 & 0.3134 & 139.4246 & 1566.6 \\
\hline & 0.20 & 0.3667 & 0.3540 & 0.3068 & 0.3068 & 356.7499 & 1560.4 & 0.2454 & 0.3093 & 108.0378 & 1564.5 \\
\hline \multirow{6}{*}{$I_{e}$} & 0 & 0.3328 & 0.3927 & 0.3235 & 0.3235 & 336.8718 & 1541.9 & 0.2454 & 0.3399 & 204.4407 & 1579.0 \\
\hline & 0.04 & 0.3597 & 0.3612 & 0.3099 & 0.3099 & 353.1681 & 1539.7 & 0.2454 & 0.3303 & 222.0491 & 1574.7 \\
\hline & 0.08 & 0.3883 & 0.3336 & 0.2981 & 0.2981 & 366.5229 & 1533.5 & 0.2454 & 0.3204 & 240.1838 & 1570.1 \\
\hline & 0.12 & 0.4187 & 0.3090 & 0.2874 & 0.2874 & 377.0340 & 1524.2 & 0.2454 & 0.3103 & 258.8950 & 1565.0 \\
\hline & 0.16 & 0.4509 & 0.2868 & 0.2785 & 0.2785 & 387.2613 & 1514.0 & 0.2454 & 0.2997 & 278.2415 & 1559.3 \\
\hline & 0.20 & 0.4850 & 0.2666 & 0.2699 & 0.2699 & 394.7127 & 1501.7 & 0.2454 & 0.2888 & 298.2927 & 1553.0 \\
\hline
\end{tabular}

that under decentralized decision, the value of $A_{s}$ has no effect on the credit period, replenishment cycle time, and the retailer's profit, while the supplier benefits from the smaller value of $A_{s}$. Moreover, under centralized decision, a smaller value of $A_{s}$ can result in a longer credit period and a shorter replenishment cycle time and, then, the total profit of supply chain increases;

(ii) Under SS model, both the credit period and replenishment cycle time increase as $A_{r}$ increases. Hence, the retailer' profit decreases due to a larger value of $A_{r}$ and the supplier's profit also decreases because the supplier must pay much more interest in a longer credit period. Under RS model, when the retailer's ordering cost increases, the credit period remains constant while the replenishment cycle time increases, which will inevitably lead to a reduction in the retailer's profit. However, since the credit period remains unchanged and the replenishment cycle time increases, the supplier's ordering cost per cycle decreases and the supplier's profit increases eventually. Based on the centralized decision, the credit period decreases, 
while the replenishment cycle time increases as $A_{r}$ increases. This shows that the smaller the value of $A_{r}$, the longer the credit period and the shorter the replenishment period. Hence, the supply chain benefits from a lower value of $A_{r}$.

The effects of $P$ and $C$ on optimal solutions are shown in Table 4. Hence, the following can be deduced from Table 3:

(i) Under SS model, both the credit period and replenishment cycle time decrease as $P$ increases. Additionally, the retailer's profit increases greatly, while the supplier's profit decreases slightly with the increase of $P$. Under RS model, the credit period remains unchanged and the replenishment cycle time decreases as $P$ increases. Therefore, the retailer's profit increases due to a larger value of $P$ and shorter replenishment period. However, the supplier's profit decreases because a shorter replenishment cycle time can add the supplier's ordering cost per cycle. Under centralized decision, the credit period increases, while the replenishment cycle time decreases with the increase of $P$. This implies that the retailer's profit increases greatly and the supplier's profit decreases slightly, while the total profit of supply chain increases eventually;

(ii) Under SS model, when the value of $C$ is less than a certain value, the credit period, replenishment cycle time, and the retailer's profit remain constant while the supplier's profit decreases as $C$ increases. However, when the value of $C$ is more than a certain value, the supplier will not choose to provide the credit period to retailer. Moreover, under this circumstance, the replenishment cycle time and retailer's profit remain unchanged and the supplier's profit decreases as $C$ increases. Under RS model, a higher value of $C$ can cause a higher value of the replenishment cycle time, while a lower value of the credit period does the opposite. In addition, both the retailer's and supplier's profits decrease as $C$ increases. Under centralized decision, the credit period decreases while the replenishment cycle time increases as $C$ increases. Then, the profit of the supply chain will decrease due to a larger production cost and a shorter credit period. Hence, both the supplier and retailer benefit from a lower production cost in any supply chain power structurers.

The influence of $V$ and $h$ on $M, T, T P_{r}$, and $T P_{s}$ is shown in Table 5. Hence, the following can be deduced from it:

(i) In SS model, both the credit period and replenishment cycle time remain constant with the increase of $V$. Therefore, the retailer's profit will inevitably decrease because of the unchanged credit period and the increase of the wholesale price. On the contrary, the supplier's profit will be increased. In RS model, the credit period increases, while the replenishment period decreases with an increase wholesale price. Although the credit period increases, for retailers, it cannot compensate for the loss caused by the rise in wholesale prices. Hence, the retailer's profit will decrease, while the supplier's profit increases as $V$ increases. In the centralized decision model, the credit period decreases, while the replenishment cycle time increases as $V$ increases. Then, the total profit of supply chain will decrease due to a higher wholesale price and a shorter credit period. Hence, in the centralized decision model, the supply chain benefits from a lower wholesale price;

(ii) Under SS model, two decision variables, i.e., trade credit period and replenishment cycle time, decrease as $h$ increases. Then, both the profit of the supplier and retailer will decrease due to the decrease of credit period and the increase of holding cost. This is understandable given the increase in profit due to the reduction of credit period cannot compensate for the loss of profit due to the increase in holding cost. Under RS model, the credit period remains unchanged, while the replenishment cycle time decreases as $h$ increases. Then, since the supplier's profit from the reduction of replenishment cycle time cannot compensate for the loss caused by the increase of holding cost, the profit of both the supplier and retailer decreases with the increase of the holding cost. Under centralized decision, both the credit period and replenishment period decrease as $h$ increases, which will lead to a reduction in the total profit of the supply chain. Therefore, in either a decentralized or centralized decision, both of supplier and retailer will benefit from a lower holding cost.

The influence of $I_{c}$ and $I_{e}$ on optimal solutions can be shown in Table 6 . Hence, the following can be deduced from Table 6 :

(i) The credit period and replenishment cycle time remain constant as $I_{c}$ increases under SS model. Hence, the retailer's profit also remains constant and the supplier's profit increases with the increase of $I_{c}$. Under RS model, the value of $I_{c}$ has no effect on the credit period, which leads to a shorter replenishment cycle time. Then, as $I_{c}$ increases, the interest payable and the supplier's ordering cost per cycle increase. Hence, the profit of both the retailer and supplier is falling. Under 
centralized decision, both the credit period and replenishment period decrease, which will lead to an increase in interest payable. Therefore, a lower interest rate is conducive to the supply chain;

(ii) Under SS model, two decision variables, trade credit period, and replenishment cycle time decrease as $I_{e}$ increases. Moreover, the retailer's profit increases, while the supplier's profit decreases with the increase of $I_{e}$. This is a good understanding, given that when $I_{e}$ increases, the retailer can make use of credit period to earn higher interest, while the supplier reaps no advantage. Hence, the supplier will provide a shorter credit period than before to reduce the interest payable during the credit period. Under RS model, as $I_{e}$ increases, the credit period keeps constant and the replenishment cycle time decreases, leading to an increase in the retailer's profit and a decrease in the supplier's profit. Under centralized decision, the credit period increases and the replenishment period decreases with the increase of $I_{e}$. This will result in an increase in the profit of both the supplier and retailer. Hence, whether it is decentralized or centralized decision, both the supplier and retailer benefit from a higher interest rate.

\subsection{The influence of parameters on the total profit of the supply chain}

The influence of parameters on optimal solutions was investigated, while the influence of parameters on total profit of supply chain remains unclear. Hence, we conduct a numerical analysis to examine the influence based on the data in Example 1. Figures 5-8 depict the effect of parameters $A_{s}, A_{r}, P, C, V, h, I_{c}$, and $I_{e}$ on the total profit of the whole supply chain.

According to Figure 5(a) and (b), the total profit of the supply chain is consistent with the same change of both $A_{s}$ and $A_{r}$. On the one hand, the total profit decreases as $A_{s}$ increases under both the decentralized and centralized decisions. On the other hand, the total profit under centralized decision is significantly greater than that under decentralized decision, and the profit of the supply chain under SS is higher than that under RS. This implies that the total profit of the supply chain benefits from the lower ordering cost of both the supplier and retailer.

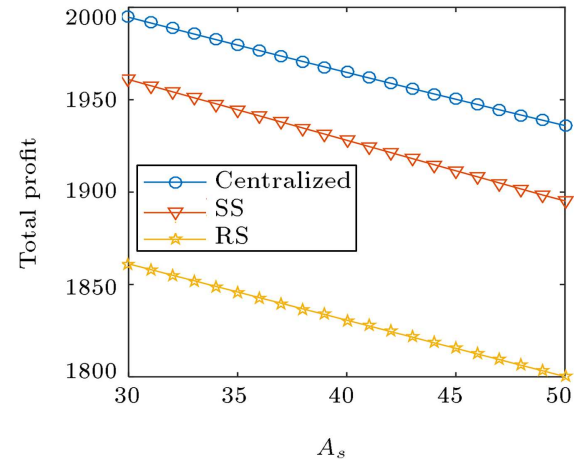

(a)

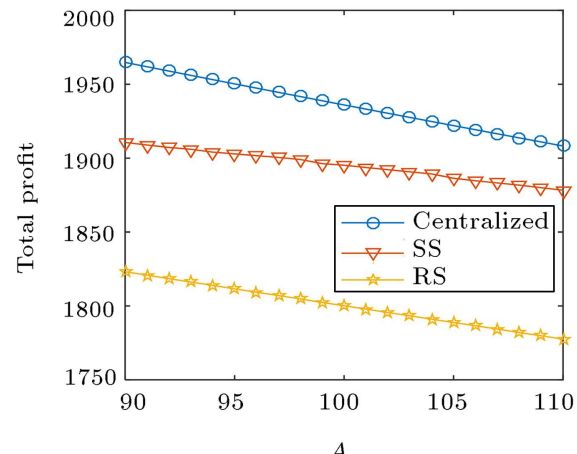

(b)

Figure 5. The influence of parameters $A_{s}$ and $A_{r}$ on the profit of the supply chain.

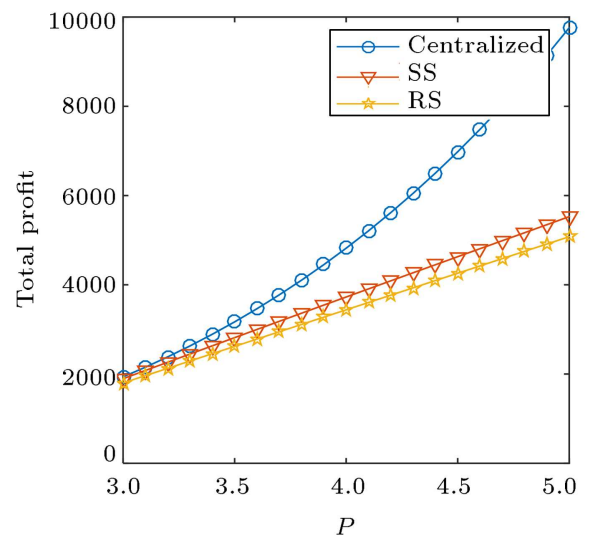

(a)

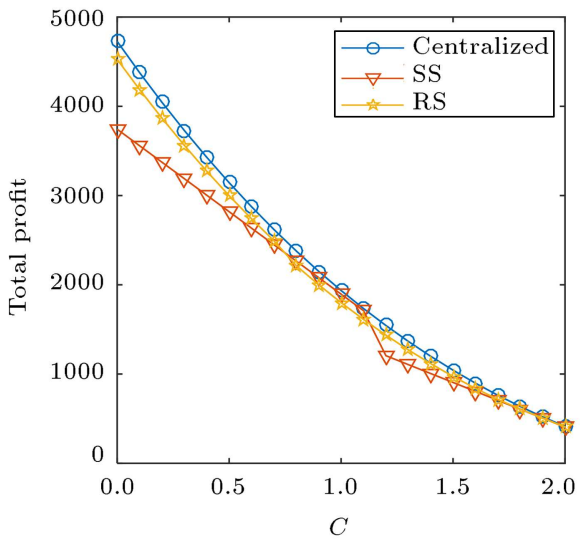

(b)

Figure 6. The influence of parameters $P$ and $C$ on the profit of the supply chain. 


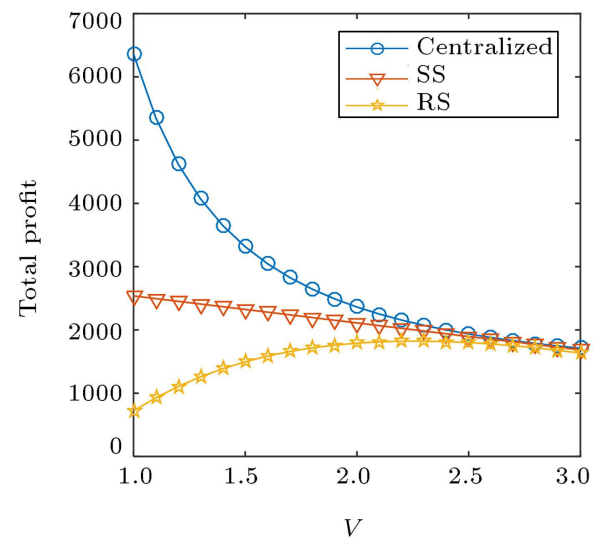

(a)

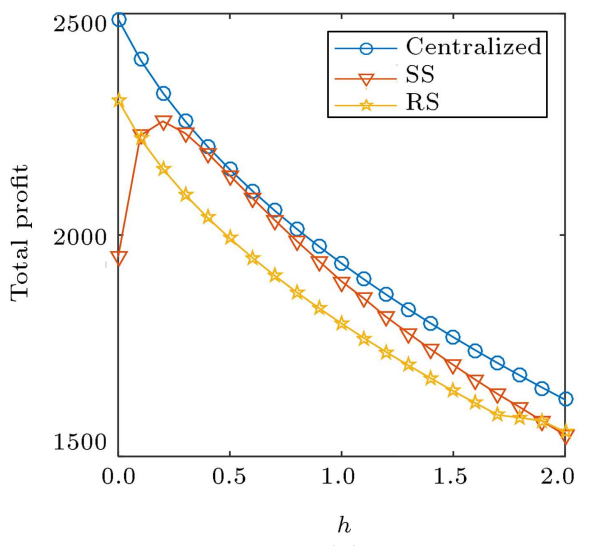

(b)

Figure 7. The influence of parameters $V$ and $h$ on the profit of the supply chain.

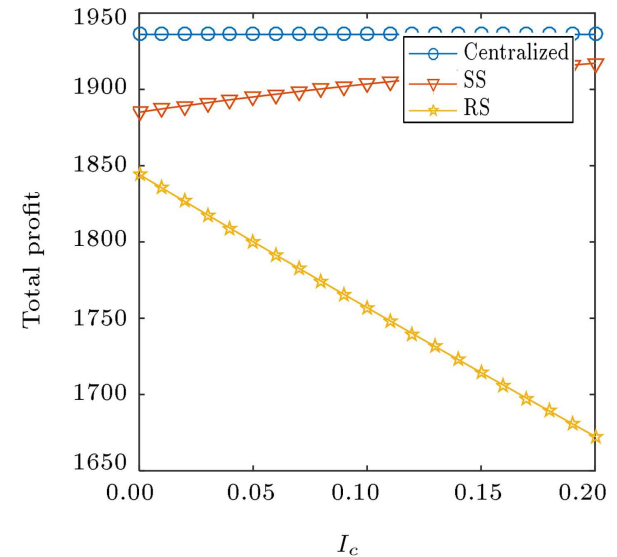

(a)

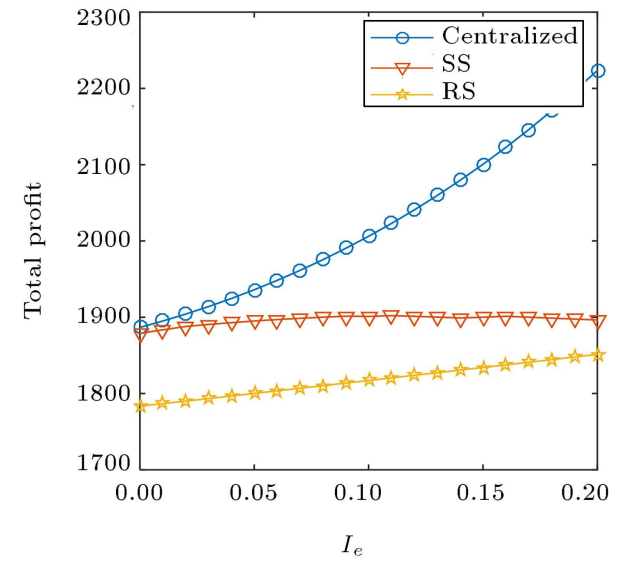

(b)

Figure 8. The influence of parameters $I_{c}$ and $I_{e}$ on the profit of the supply chain.

From Figure 6(a), on the one hand, we find that $T P_{s c}^{c *}>T P_{s c}^{s s *}>T P_{s c}^{r s *}$ as $P$ increases. On the other hand, the total profit of the supply chain increases under each decision circumstance. Figure 6(b) shows that the total profit under centralized decision is slightly larger than that under both SS and RS models. When the value of $C$ varies between two certain values, we find that the total profit under model is much more than that under SS model. Besides, when the value of $C$ is more than a certain value, the supplier does not provide credit period to the retailer and the result is opposite. Hence, the supply chain benefits from a higher retail price and a lower production cost.

According to Figure 7(a), we find that $T P_{s c}^{c *}>$ $T P_{s c}^{s s *}>T P_{s c}^{r s *}$ as $V$ increases. Besides, the total profit of supply chain decreases upon increase in the wholesale price under both SS model and centralized decision. Besides, under RS model, the total profit increases at first and then, decreases with an increase in the wholesale price. When $V \approx 2.3$, the total profit of the supply chain is maximized. Figure $7(\mathrm{~b})$ shows that under centralized decision and RS model, the total profit decreases as $h$ increases. Under SS model, the total profit increases first and then, decreases upon increase in the holding cost. When $h \approx 0.2$, the total profit will reach maximum. Hence, the supply chain benefits from a lower wholesale price and holding cost.

The total profit of the supply chain under centralized decision is found to be higher than that under both SS and RS models, as can be seen in Figure 8(a) and 8(b). Additionally, from Figure 8(a), the profit under centralized decision and RS model decreases, while it increases under SS model as $I_{c}$ increases. Figure 8(b) shows that the total profit increases under both the centralized decision and RS model while it remains basically unchanged under SS model. This implies that the supply chain benefits from a lower value of interest payable and a higher value of interest earned.

Overall, we can conclude from Tables 3-6 and figures that:

(i) The parameters $P$ and $I_{e}$ have a positive effect on the total profit of supply chain, while the remaining parameters have a negative effect on 
it. It is shown that in reality, firms should raise price and interest earned, or reduce related costs and interest payable to improve their own profit;

(ii) By comparing the optimal results under SS and RS, we can find that when the value of the credit period is greater than zero, the profit of the supply chain under SS is greater than that under RS. In other words, under the condition of trade credit period, SS model is better for the whole supply chain. However, when the supplier does not offer the trade credit period, RS model is better for the whole supply chain;

(iii) After comparing the optimal values of the decentralized decision and centralized decision, we can find that the total profit of the centralized supply chain is always higher than that of two decentralized cases. This indicates that under the condition of trade credit, the centralized decision of supplier and retailer is more conductive to the benefit of the supply chain.

\section{Conclusions}

This paper established a supplier-retailer replenishment model in which the credit period had a positive impact on the demand rate to determine the optimal solutions under different supply chain structures. In addition, the profit function of the supplier and retailer under different conditions was established according to the relationship between the trade credit period and the replenishment cycle time. Then, the optimal retailer's replenishment cycle time was obtained according to the theorems. Finally, the optimal solutions could be obtained by using the method of profit maximization. Moreover, this paper simultaneously considered the supplier's and retailer's profits. This is also the main feature of this study. Then, the optimal strategies for the retailer and the supplier were derived in different supply chain structures. It was found that a higher values of the supplier's ordering cost and supplier's production cost could cause a lower value of the profit of the supply chain under both the decentralized and centralized decisions. However, a higher value of the retailer's retail price increases the profit of the supply chain under each power structure. Besides, the whole supply chain will benefit from a lower wholesale price and holding cost. The higher the value of the interest rate, the higher the profit of the supply chain under the centralized decision and the lower the profit under the decentralized decision.

In addition, there are some managerial implications. On the one hand, the supplier and the retailer should adopt different strategies under different conditions, which can not only improve their own profit, but also optimize the management of supply chain. For example, when the supplier does not offer trade credit period to the retailer, the retailer can get the optimal profit solution under the Retailer Stackelberg model. On the other hand, in terms of the date, it is clear that the profit of the supply chain under the centralized decision is far greater than that under the decentralized decision; therefore, the supplier and the retailer should make joint decisions to optimize the supply chain.

In future research, we will investigate the twolevel trade credit policy in order to understand the effect of the trade credit period offered by the retailer on channel strategies. Then, we will extend the model with the consideration of other demand functions such as price-credit demand, etc. Finally, the permissible delay may result in default risk to suppliers, which is an issue that deserves to be studied.

\section{Acknowledgments}

The research has been supported by the Scientific Research Foundation of Nanjing University of Posts and Telecommunications (NY220212,NY219117), the Postgraduate Research \& Practice Innovation Program of Jiangsu Province (KYCX18 0941), the Humanity and Social Science Youth Foundation of Ministry of Education of China (20YJC630033), and the National Natural Science Foundation of China (71501128, 71632008).

\section{References}

1. Williams, F. "World Bank urged to lift trade credit finance", Financial Times (November 11). https://www.ft.com/content/9ebcdfaa-b012-11dda795-0000779fd18c (2008).

2. Federal Reserve Board, Financial Accounts of the United States, Accessed September 18, 2016. http://www.federalreserve.gov/releases/ z1/current/z1.pdf (2016).

3. Quick, B. "A snack maker's unsavory business practices", Fortune, 168(4), p. 54 (2013).

4. Beranek, W. "Financial implications of lot-size inventory models", Management Science, 13, pp. 401-408 (1967).

5. Goyal, S.K. "Economic order quantity under conditions of permissible delay in payments", Journal of the Operational Research Society, 36, pp. 335-338 (1985).

6. Jamal, A.M.M. and Wang, S. "An ordering policy for deteriorating items with allowable shortage and permissible delay in payments", Journal of the Operational Research Society, 84, pp. 826-833 (1997).

7. Dye, C.Y. "A deteriorating inventory model with stock-dependent demand rate and partial backlogging under conditions of permissible delay in payments", Operations Research, 39, pp. 189-201 (2002). 
8. Huang, Y.F. "Economic order quantity under conditionally permissible delay in payments", European Journal of Operational Research, 176, pp. 911-924 (2007).

9. Huang, Y.F. and Hsu, K.H. "An EOQ model under retailer partial trade credit policy in supply chain", International Journal of Production Economics, 112, pp. 655-664 (2008).

10. Gupta, D. and Wang, L. "A stochastic inventory model with trade credit", Manufacturing \& Service Operations Management, 11, pp. 4-18 (2009).

11. Jaggi, C.K. and Kausar, A. "Retailer's optimal credit and replenishment policy for deteriorating items with credit linked demand in a supply chain", International Journal of Applied Decision Sciences, 3(2), p. 117 (2010).

12. Jaggi, C.K., Kapur, P.K., Goyal, S.K., et al. "Optimal replenishment and credit policy in EOQ model under two-levels of trade credit policy when demand is influenced by credit period", International Journal of System Assurance Engineering and Management, 3(4), pp. 352-359 (2012).

13. Teng, J.T., Min, J., and Pan, Q. "Economic order quantity model with trade credit financing for nondecreasing demand", Omega, 40, pp. 328-335 (2012).

14. Kumar Sett, B., Sarkar, B., and Goswami, A. "A twowarehouse inventory model with increasing demand and time varying deterioration", Scientia Iranica, 19(6), pp. 1969-1977 (2012).

15. Jaggi, C.K., Goel, S.K., and Mittal, M. "Credit financing in economic ordering policies for detective items with allowable shortages", Applied Mathematics and Computation, 219, pp. 5268-5282 (2013).

16. Lou, K.R. and Wang, W.C. "Optimal trade credit and order quantity when trade credit impacts on both demand rate and default risk", Journal of the Operational Research Society, 64, pp. 1551-1556 (2013).

17. Wang, W.C., Teng, J.T., and Lou, K.R. "Seller's optimal credit period and cycle time in a supply chain for deteriorating items with maximum lifetime", European Journal of Operational Research, 232, pp. 315-321 (2014).

18. Teng, J.T., Lou, K.R., and Wang, L. "Optimal trade credit and lot size policies in economic production quantity models with learning curve production costs", International Journal of Production Economics, $\mathbf{1 5 5}$, pp. 318-323 (2014).

19. Kumar, M. and Triphthi, R.P. "A new model for deteriorating items with inflation under permissible delay in payments", International Journal of Industrial Engineering Computations, 5, pp. 365-374 (2014).

20. Jaggi, C.K., Yadavalli, V.S.S., Verma, M., et al. "An EOQ model with allowable shortage under trade credit in different scenario", Applied Mathematics and Computation, 252, pp. 541-551 (2015).
21. Khanna, A., Gautam, P., and Jaggi, C.K. "Inventory modeling for deteriorating imperfect quality items with selling price dependent demand and shortage backordering under credit financing", International Journal of Mathematical, Engineering and Management Sciences, 2(2), pp. 110-124 (2015).

22. Khanna, A., Jaggi, C.K., and Gautam, P. "Coordinating vendor-buyer decisions for imperfect quality items considering trade credit and fully backlogged shortages", AIP Conference Proceedings, 1715 (2015).

23. Khanna, A., Mittal, M., Gautam, P., et al. "Credit financing for deteriorating imperfect quality items with allowable shortages", Decision Science Letters, 5(1), pp. 45-60 (2016).

24. Peura, H., Yang, S.A., and Lai, G. "Trade credit in competition: a horizontal benefit", Manufacturing \& Service Operations Management, 19(2), pp. 263-289 (2017).

25. Chen, Z. and Zhang, R.Q. "A capital flow-constrained lot-sizing problem with trade credit", Scientia Iranica, 25(5), pp. 2775-2787 (2018).

26. Jaggi, C.K., Gautam, P., and Khanna, A. "Inventory decisions for imperfect quality deteriorating items with exponential declining demand under trade credit and partially backlogged shortages", Quality, IT and Business Operations, pp. 213-229 (2018).

27. Jaggi, C.K., Mamta, G., and Amrina, K. "Credit policies for deteriorating imperfect quality items with exponentially increasing demand and partial backlogging", Handbook of Research on Promoting Business Process Improvement Through Inventory Control Techniques, pp. 90-106, IGI Global (2018).

28. Kouvelis, P. and Zhao, W.H. "Who should finance the supply chain? Impact of credit ratings on supply chain decisions", Manufacturing \& Service Operations Management, 20(1), pp. 19-35 (2018).

29. Feng, L., Tao, J., Feng, W., et al. "Impacts of twostage deterioration on an integrated inventory model under trade credit and variable capacity utilization", European Journal of Operational Research, 272(1), pp. 219-234 (2019).

30. Zhou, Y.W. and Zhou, D. "Determination of the optimal trade credit policy: a supplier-stackelberg model", Journal of the Operational Research Society, 64, pp. 1030-1048 (2013).

31. Chern, M.S., Pan, Q., Teng, J.T., et al. "Stackelberg solution in a vendor-buyer supply chain model with permissible delay in payments", International Journal of Production Economics, 144, pp. 397-404 (2013).

32. Hoseininia, M., Didehvar, F., and Esfahani, M.M.S. "Inventory competition in a multi channel distribution system: the Nash and stackelberg game", Scientia Iranica, 20(3), pp. 846-854 (2013).

33. Chern, M.S., Chan, Y.L., Teng, J.T., et al. "Nash equilibrium solution in a vendor-buyer supply chain model with permissible delay in payments", Computers \& Industrial Engineering, 70, pp. 116-123 (2014). 
34. Tsao, Y.C., Lu, J.C., An, N., et al. "Retailer shelfspace management with trade allowance: a stackelberg game between retailer and manufacturers", International Journal of Production Economics, 148(148), pp. 133-144 (2014).

35. Wu, C., Zhao, Q., and Xi, M. "A retailer-supplier supply chain model with trade credit default risk in a supplier-stackelberg game", Computers \& Industrial Engineering, 112, pp. 568-575 (2017).

36. Chua, F.L.S., Vasnani, N.N., Pacio, L.B.M., et al. "A stackelberg game in multi-period planning of maketo-order production system across the supply chain", Journal of Manufacturing Systems, 46, pp. 231-246 (2018).

37. Jaggi, C.K., Mamta, G., Amrina, K., et al. "Inventory and credit decisions for deteriorating items with displayed stock dependent demand in two-echelon supply chain using Stackelberg and Nash equilibrium solution", Annals of Operations Research, 274, pp. 309-329 (2018).

38. Nazari, L., Seifbarghy, M., and Setak, M. "Modeling and analyzing pricing and inventory problem in a closed-loop supply chain with return policy and multiple manufacturers and multiple sales channels using game theory", Scientia Iranica, 25(5), pp. 2759-2774 (2018).

39. Pal, B., Sana, S.S., and Chaudhuri, K. "Twoechelon manufacturer-retailer supply chain strategies with price, quality, and promotional effort sensitive demand", International Transactions in Operational Research, 22(6), pp. 1071-1095 (2015).

40. Wang, Y., Sun, X., and Meng, F. "On the conditional and partial trade credit policy with capital constraints: a stackelberg model", Applied Mathematical Modelling, 40(1), pp. 1-18 (2016).

41. Xiao, T., Choi, T.M., and Cheng, T.C.E. "Product variety and channel structure strategy for a retailerstackelberg supply chain", European Journal of Operational Research, 233(1), pp. 114-124 (2014).

42. Yang, S.A. and Birge, J.R. "Trade credit, risk sharing, and inventory financing portfolios", Management Science, 64(8), pp. 3667-3689 (2017).

43. Lee, H.H., Zhou, J., and Wang, J. "Trade credit financing under competition and its impact on firm performance in supply chains", Manufacturing \& Service Operations Management, 20(1), pp. 36-52 (2018).

44. Jaggi, C.K., Goyal, S.K., and Goel, S.K. "Retailer's optimal replenishment decisions with credit-linked demand under permissible delay in payments", European Journal of Operational Research, 190, pp. 130-135 (2008).

45. Abad, P.L. and Jaggi, C.K. "A joint approach for setting unit price and the length of the credit period for a seller when end demand is price sensitive", International Journal of Production Economics, 83, pp. 115-122 (2003).
46. Ho, C.H. "The optimal integrated inventory policy with price-and-credit-linked demand under two-level trade credit", Computers and Industrial Engineering, 60(1), pp. 117-126 (2011).

\section{Appendix}

Proof of Section 5.1.1

Upon calculation, we have:

$$
\begin{aligned}
& \frac{\partial T P_{r}^{(1)}}{\partial T}=\frac{A_{r}}{T^{2}}-\frac{D\left(h+V I_{c}\right)}{2}-\frac{D M^{2}\left(P I_{e}-V I_{c}\right)}{2 T^{2}} \\
& \frac{\partial^{2} T P_{r}^{(1)}}{\partial T^{2}}=-\frac{2 A_{r}}{T^{3}}+\frac{D M^{2}\left(P I_{e}-V I_{c}\right)}{T^{3}}
\end{aligned}
$$

If $D M^{2}\left(P I_{e}-V I_{c}\right)-2 A_{r}<0$, then $\partial^{2} T P_{r} / \partial T^{2}<0$ and $T P_{r}{ }^{(1)}$ is concave in $T$; thus, we can obtain:

$$
T^{*}=\sqrt{\frac{2 A_{r}-D M^{2}\left(P I_{e}-V I_{c}\right)}{h D+V I_{c} D}} .
$$

Considering the first and second derivatives of Eq. (2), we have:

$$
\begin{aligned}
& \frac{\partial T P_{r}^{(2)}}{\partial T}=\frac{A_{r}}{T^{2}}-\frac{h D}{2}-\frac{P I_{e} D}{2} \\
& \frac{\partial^{2} T P_{r}^{(2)}}{\partial T^{2}}=-\frac{2 A_{r}}{T^{3}}<0 .
\end{aligned}
$$

Since the retailer's ordering cost is $A_{r}>0$ and the replenishment cycle time is $T>0, T P_{r}^{(2)}$ is concave in $T$; thus, we can get:

$$
T^{*}=\sqrt{\frac{2 A_{r}}{h D+P I_{e} D}} .
$$

\section{Proof of Theorem 1}

If $2 A_{r}-D M^{2}\left(P I_{e}+h\right)>0$, then we will know that $\partial^{2} T P_{r}^{(1)}(T \mid M) / \partial T^{2}<0$ for $M \leq T$, which implies the retailer's profit is strictly decreasing in $T$. In addition, for $M \leq T$, we can get $\partial T P_{r}{ }^{(1)}(M \mid M) / \partial T=2 A_{r}-D M^{2}\left(P I_{e}+h\right) / 2 M^{2}>$ 0 , and $\partial T P_{r}{ }^{(1)}(\infty \mid M) / \partial T=-D\left(h+V I_{c}\right) / 2<0$. Consequently, there exists a unique $T^{*}>M$ such that $T P_{r}{ }^{(1)}\left(T^{*}\right) \geq T P_{r}{ }^{(1)}(T)$ for all $M \leq T$.

Similarly, for $M \geq T$, we have:

$$
\partial^{2} T P_{r}^{(2)}(T \mid M) / \partial T^{2}<0, \quad \partial T P_{r}{ }^{(2)}(0 \mid M) / \partial T=\infty,
$$

and:

$$
\partial T P_{r}^{(2)}(M \mid M) / \partial T=2 A_{r}-D M^{2}\left(h+P I_{e}\right) / 2 M^{2}>0 .
$$


Therefore, we have $T P_{r}^{(2)}(M) \geq T P_{r}^{(2)}(T)$ for all $M \geq T$.

Then, we have $T P_{r}^{(2)}\left(T^{*}\right) \geq T P_{r}{ }^{(2)}(M) \geq$ $T P_{r}{ }^{(2)}(T)$ for all $M \geq T$.

Likewise, if $2 A_{r}-D M^{2}\left(P I_{e}+h\right)<0$, then we can know that:

$$
\partial T P_{r}{ }^{(1)}(M \mid M) / \partial T=2 A_{r}-D M^{2}\left(P I_{e}+h\right) / 2 M^{2}<0
$$

and:

$$
\partial T P_{r}^{(1)}(\infty \mid M) / \partial T=-D\left(h+V I_{c}\right) / 2<0 .
$$

Hence, we can know that $\partial T P_{r}{ }^{(1)}(T \mid M) / \partial T<0$ and $T P_{r}^{(1)}(M) \geq T P_{r}{ }^{(1)}(T)$ for all $M \leq T$.

Similarly, for $M \geq T$, if $2 A_{r}-D M^{2}\left(P I_{e}+h\right)<$ 0 , then we can know that $\partial T P_{r}{ }^{(2)}(0 \mid M) / \partial T=\infty$ and $\partial T P_{r}{ }^{(2)}(M \mid M) / \partial T=2 A_{r}-D M^{2}\left(h+P I_{e}\right) / 2 M^{2}<0$. Consequently, it is realized that there is a unique $T^{*}<$ $M$ such that $T P_{r}{ }^{(2)}\left(T^{*}\right) \geq T P_{r}^{(2)}(T)$ for all $M \geq T$.

Thus, we can get $T P_{r}^{(2)}\left(T^{*}\right) \geq T P_{r}^{(2)}(M) \geq$ $T P_{r}{ }^{(2)}(T)$ for all $M \geq T$.

This completes the proof of Theorem 1.

\section{Proof of Section 5.1.2}

By calculating the first-order derivatives of Eq. (6) with respect to $M$, we have the relation shown in Box A.I.

In the case of $M \geq T$, we can know that $2 A_{r}$ $D M^{2}\left(P I_{e}-V I_{c}\right)>0$. According to Assumption 5, we can know that $a>0, b>0$. According to the above assumption $P I_{e}>V I_{c}$, we can derive that $T P_{s}{ }^{(1)}$ is the decreasing function of $M$ when $M \leq T$. Hence, the maximum of $T P_{s}$ over the interval [0,T] is $T P_{s}^{(1)}(M=$ $0)$. Thus, the optimal trade credit is $M^{*}=0$.

Taking the first derivative into Eq. (10), we have:

$$
\begin{aligned}
\frac{\partial T P_{s}^{(2)}}{\partial M}= & k e^{\alpha M}[\alpha V-\alpha C-\alpha V M(a+b M) \\
& -a V-2 b V M]-\alpha A_{s} \sqrt{\frac{k e^{\alpha M}\left(h+P I_{e}\right)}{8 A_{r}}} .
\end{aligned}
$$

According to Assumptions 4 and 5, we can be known that $a>0, b>0, D=k e^{\alpha M}>0$; therefore, we find that $T P_{s}{ }^{(2)}$ is a decreasing function of $M$ when $M \geq T$. Hence, the maximization of $T P_{s}{ }^{(2)}$ over the interval $[T,+\infty]$ is $T P_{s}{ }^{(2)}(M=T)$. Therefore, the optimal trade credit is $M^{*}=T=\sqrt{\frac{2 A_{r}}{\left(h+P I_{e}\right) k e^{\alpha M}}}$.

\section{Proof of Section 5.2.1}

By calculation, we have:

$$
\begin{aligned}
\frac{\partial T P_{s}}{\partial M}= & k e^{\alpha M}[\alpha V-\alpha C-\alpha V M(a+b M) \\
& -a V-2 b V M] \\
\frac{\partial^{2} T P_{s}}{\partial M^{2}}= & k e^{\alpha M}\left[\alpha^{2} V-\alpha^{2} C-\alpha^{2} V M(a+b M)\right. \\
& -2 a \alpha V-4 \alpha b V M-2 b V] .
\end{aligned}
$$

According to Assumption 5 and the above assumption $P I_{e}>V I_{c}$ that $\partial^{2} T P_{s} / \partial M^{2}<0$, which means $T P_{s}$ is concave in $M$, we can get by the equation shown in Box A.II.

\section{Proof of Section 5.2.2}

By calculation of the first-order and second-order derivations of $T P_{r}^{(1)}$ by $T$, we have:

$$
\frac{\partial T P_{r}^{(1)}}{\partial T}=\frac{A_{r}}{T^{2}}-\frac{k e^{\alpha M^{*}}\left(h+V I_{c}\right)}{2}
$$

$$
\begin{aligned}
& \frac{\partial T P_{s}^{(1)}}{\partial M}=k e^{\alpha M}[\alpha V-\alpha C-\alpha V M(a+b M)-a V-2 b V M] \\
& \quad-\frac{A_{s} \sqrt{k e^{\alpha M}\left(h+V I_{c}\right)}\left\{\alpha\left[2 A_{r}-M^{2} k e^{\alpha M}\left(P I_{e}-V I_{c}\right)\right]+k e^{\alpha M} M\left(P I_{e}-V I_{c}\right)(\alpha M+2)\right\}}{2\left[2 A_{r}-k e^{\alpha M} M^{2}\left(P I_{e}-V I_{c}\right)\right]^{3 / 2}} .
\end{aligned}
$$

Box A.I

$$
M^{*}=\frac{-(\alpha a V+2 b V)+\sqrt{(\alpha a V+2 b V)^{2}-4 \alpha b V(a V-\alpha V+\alpha C)}}{2 \alpha b V} .
$$




$$
\begin{gathered}
-\frac{\left(P I_{e}-V I_{c}\right) k e^{\alpha M^{*}} M^{*^{2}}}{2 T^{2}}, \\
\frac{\partial^{2} T P_{r}^{(1)}}{\partial T^{2}}=-\frac{2 A_{r}}{T^{3}}+\frac{\left(P I_{e}-V I_{c}\right) k e^{\alpha M^{*}} M^{*^{2}}}{T^{3}} .
\end{gathered}
$$

If $\left(P I_{e}-V I_{c}\right) k e^{\alpha M^{*}} M^{*^{2}}-2 A_{r}<0$, then $T P_{r}^{(1)}$ is concave in $T$; thus, we obtain:

$$
T^{*}=\sqrt{\frac{2 A_{r}-\left(P I_{e}-V I_{c}\right) k e^{\alpha M^{*}} M^{*^{2}}}{\left(h+V I_{c}\right) k e^{\alpha M^{*}}}} .
$$

Taking the first and second derivatives of Eq. (19), we have:

$$
\begin{aligned}
& \frac{\partial T P_{r}^{(2)}}{\partial T}=\frac{A_{r}}{T^{2}}-\frac{\left(h+P I_{e}\right) k e^{\alpha M^{*}}}{2}, \\
& \frac{\partial^{2} T P_{r}^{(2)}}{\partial T^{2}}=-\frac{2 A_{r}}{T^{3}}<0 .
\end{aligned}
$$

Since $\partial^{2} T P_{r}^{(2)} / \partial T^{2}<0, T P_{r}^{(2)}$ is concave in $T$, we can get:

$$
T^{*}=\sqrt{\frac{2 A_{r}}{\left(h+P I_{e}\right) k e^{\alpha M^{*}}}} .
$$

\section{Proof of Theorem 2}

Similar to the proof of Theorem 1, assuming $\Delta_{2}=2 A_{r}-$ $k e^{\alpha M^{*}} M^{*^{2}}\left(P I_{e}+h\right)$, for any given $T$, we obtain: If $2 A_{r}-k e^{\alpha M^{*}} M^{*^{2}}\left(P I_{e}+h\right)>0$, then we can know that $\partial^{2} T P_{r}^{(1)} T / \partial T^{2}<0$ for $M \leq T$. In addition, we can get that $\partial T P_{r}^{(1)}(M) / \partial T>0$ and $\partial T P_{r}{ }^{(1)}(\infty) / \partial T<$ 0 . Hence, there exists a unique $T^{*}>M^{*}$ such that $T P_{r}^{(1)}\left(T^{*}\right) \geq T P_{r}^{(1)}(T)$ for all $M \leq T$. Similarly, for $M \geq T$, we can know that $T P_{r}$ is an increasing function for all $M \geq T$. Therefore, we have $T P_{r}^{(1)}(M) \geq$ $T P_{r}{ }^{(1)}(T)$ and $T P_{r}{ }^{(1)}\left(T^{*}\right) \geq T P_{r}{ }^{(1)}(M) \geq T P_{r}{ }^{(1)}(T)$ for all $M \geq T$.

Likewise, if $2 A_{r}-D M^{2}\left(P I_{e}+h\right)<0$, we can get $T P_{r}{ }^{(2)}\left(T^{*}\right) \geq T P_{r}^{(2)}(M) \geq T P_{r}{ }^{(2)}(T)$ for all $M \leq T$.

This completes the proof of Theorem 2 .

\section{Proof of Theorem 3}

By calculating the first and second orders of $T P_{s c}$ by $T$, we obtain:

$$
\begin{aligned}
& \frac{\partial T P_{s c}}{\partial T}= \frac{A_{r}+A_{s}}{T^{2}}-\frac{k e^{\alpha M}\left(h+V I_{c}\right)}{2} \\
&-\frac{k e^{\alpha M} M^{2}\left(P I_{e}-V I_{c}\right)}{2 T^{2}}, \\
& \frac{\partial^{2} T P_{s c}}{\partial T^{2}}= \frac{k e^{\alpha M} M^{2}\left(P I_{e}-V I_{c}\right)-2\left(A_{r}+A_{s}\right)}{T^{3}}, \\
& \frac{\partial T P_{s c}}{\partial M}= \alpha k e^{\alpha M}\left[P-C-\frac{T\left(h+V I_{c}\right)}{2}\right] \\
&+k e^{\alpha M}\left[\frac{\left(P I_{e}-V I_{c}\right)\left(\alpha M^{2}+2 M\right)}{2 T}\right. \\
&\left.+\left(I_{c}-a-b M\right)(\alpha V M+V)-b V M\right], \\
& \frac{\partial^{2} T P_{s c}}{\partial M^{2}}= k e^{\alpha M}\left\{\alpha^{2}\left[P-C-\frac{T\left(h+V I_{c}\right)}{2}\right]\right. \\
&+\frac{\left(P I_{e}-V I_{c}\right)\left(\alpha^{2} M^{2}+4 \alpha M+2\right)}{2 T} \\
&+\left(I_{c}-a-b M\right)\left(\alpha^{2} V M+2 \alpha V\right) \\
&-2 \alpha b V M-2 b V\}, \\
& \frac{\partial^{2} T P_{s c}}{\partial T \partial M}= \frac{\partial^{2} T P_{s c}}{\partial M \partial T}=-k e^{\alpha M}\left[\frac{\alpha\left(h+V I_{c}\right)}{2}\right. \\
&+\left(\alpha M^{2}+2 M\right)\left(P I_{e}-V I_{c}\right) \\
& 2 T^{2}
\end{aligned} .
$$

The optimal solutions are achieved by the equations shown in Box A.III. Then, we can know that the

$$
\begin{aligned}
& T^{*}=\sqrt{\frac{2\left(A_{r}+A_{s}\right)-k e^{\alpha M} M^{2}\left(P I_{e}-V I_{c}\right)}{k e^{\alpha M}\left(h+V I_{c}\right)}} . \\
& M^{*}=\frac{-2\left[\left(P I_{e}-V I_{c}\right)+\left(I_{c}-a\right) \alpha V T-2 b V T\right]}{2 \alpha\left(P I_{e}-V I_{c}-2 b V T\right)} \\
& +\frac{\sqrt{4\left[\left(P I_{e}-V I_{c}\right)+\left(I_{c}-a\right) \alpha V T-2 b V T\right]^{2}-8 \alpha\left(P I_{e}-V I_{c}-2 b V T\right)\left[2 T V\left(I_{c}-a\right)+\alpha T\left(2 P-2 C-h T-V I_{c} T\right)\right]}}{2 \alpha\left(P I_{e}-V I_{c}-2 b V T\right)} .
\end{aligned}
$$




$$
\begin{aligned}
M^{*}= & \frac{2 \alpha P I_{e}-2 \alpha a V-4 b V}{4 \alpha b V} \\
& +\frac{\sqrt{4\left(\alpha P I_{e}-\alpha a V-2 b V\right)^{2}-16 \alpha b V\left[P I_{e} T \alpha-2 P I_{e}+2 a V-\alpha(2 P-2 C-T h)\right]}}{4 \alpha b V} .
\end{aligned}
$$

Box A.IV

Hessian matrix is as follows:

$$
\begin{aligned}
|H| & =\left|\begin{array}{cc}
\frac{\partial^{2} T P_{s c}}{\partial M^{2}} & \frac{\partial^{2} T P_{s c}}{\partial M \partial T} \\
\frac{\partial^{2} T P_{s c}}{\partial T \partial M} & \frac{\partial^{2} T P_{s c}}{\partial T^{2}}
\end{array}\right| \\
& =k e^{\alpha M}\left\{\alpha^{2}\left[P-C-\frac{T\left(h+V I_{c}\right)}{2}\right]\right. \\
& +\frac{\left(P I_{e}-V I_{c}\right)\left(\alpha^{2} M^{2}+4 \alpha M+2\right)}{2 T} \\
& \left.+\left(I_{c}-a-b M\right)\left(\alpha^{2} V M+2 \alpha V\right)-2 \alpha b V M-2 b V\right\} \\
& \times \frac{k e^{\alpha M} M^{2}\left(P I_{e}-V I_{c}\right)-2\left(A_{r}+A_{s}\right)}{T^{3}}-\left\{k e^{\alpha M}\right. \\
& {\left.\left[\frac{\alpha\left(h+V I_{c}\right)}{2}+\frac{\left(\alpha M^{2}+2 M\right)\left(P I_{e}-V I_{c}\right)}{2 T^{2}}\right]\right\}^{2} } \\
& =W_{1}+W_{2} .
\end{aligned}
$$

Since the optimal retailer's replenishment cycle time $T^{*}>0$, then $2\left(A_{r}+A_{s}\right)-k e^{\alpha M} M^{2}\left(P I_{e}-V I_{c}\right)>$ 0 and $\partial^{2} T P_{s c} / \partial T^{2}<0$. If $W_{1}+W_{2} \geq 0$, then $\partial^{2} T P_{s c} / \partial M^{2}<0$ and $|H| \geq 0$.

This completes the proof of Theorem 3 .

\section{Proof of Theorem 4}

By calculating the first and second derivations of $T P_{s c}$ by $T$, we obtain:

$$
\begin{aligned}
& \frac{\partial T P_{s c}}{\partial T}=\frac{A_{r}+A_{s}}{T^{2}}-\frac{k e^{\alpha M}\left(h+P I_{e}\right)}{2}, \\
& \frac{\partial^{2} T P_{s c}}{\partial T^{2}}=-\frac{2\left(A_{r}+A_{s}\right)}{T^{3}}, \\
& \frac{\partial T P_{s c}}{\partial M}=\alpha k e^{\alpha M}\left[P-C-\frac{T h}{2}-V M(a+b M)\right. \\
& \left.\quad+\frac{P I_{e}(2 M-T)}{2}\right]+k e^{\alpha M}\left[P I_{e}-V(a+2 b M)\right],
\end{aligned}
$$

$$
\begin{aligned}
\frac{\partial^{2} T P_{s c}}{\partial M^{2}}= & \alpha k e^{\alpha M}\left[\alpha\left(P-C-\frac{T h}{2}\right)\right. \\
& +\frac{\alpha P I_{e}(2 M-T)}{2}-\alpha V M(a+b M) \\
& \left.+2 P I_{e}-2 V(a+2 b M)\right]-2 k e^{\alpha M} b V, \\
\frac{\partial^{2} T P_{s c}}{\partial T \partial M}= & \frac{\partial^{2} T P_{s c}}{\partial M \partial T}=-\frac{\alpha k e^{\alpha M}\left(h+P I_{e}\right)}{2} .
\end{aligned}
$$

Since $T P_{s c}$ is concave in $T$, the optimal retailer's replenishment cycle time is:

$$
T^{*}=\sqrt{\frac{2\left(A_{r}+A_{s}\right)}{k e^{\alpha M}\left(h+P I_{e}\right)}} .
$$

Then, we obtain the equation shown in Box A.IV. Then, we can know that the Hessian matrix is:

$$
\begin{aligned}
|H| & =\left|\begin{array}{cc}
\frac{\partial^{2} T P_{s c}}{\partial M^{2}} & \frac{\partial^{2} T P_{s c}}{\partial M \partial T} \\
\frac{\partial^{2} T P_{s c}}{\partial T \partial M} & \frac{\partial^{2} T P_{s c}}{\partial T^{2}}
\end{array}\right| \\
& =-\frac{2\left(A_{r}+A_{s}\right)}{T^{3}} \times\left\{\alpha k e ^ { \alpha M } \left[\alpha\left(P-C-\frac{T h}{2}\right)\right.\right. \\
& +\frac{\alpha P I_{e}(2 M-T)}{2}-\alpha V M(a+b M)+2 P I_{e} \\
& \left.-2 V(a+2 b M)]-2 k e^{a M} b V\right\} \\
& -\left[\frac{\alpha k e^{\alpha M}\left(h+P I_{e}\right)}{2}\right]^{2}=W_{3}+W_{4} .
\end{aligned}
$$

Since $\partial^{2} T P_{s c} / \partial T^{2}<0$, if $W_{3}+W_{4} \geq 0$, we have $\partial^{2} T P_{s c} / \partial M^{2}<0$ and $|H| \geq 0$.

This completes the proof of Theorem 4 .

\section{Biographies}

Chong Zhang received his $\mathrm{PhD}$ degree in Systems Engineering from the School of Economics and Management in Southeast University, China in 2012. During his doctoral studies, he joined as a $\mathrm{PhD}$ Research 
Scholar at Worcester Polytechnic Institute for one year. Currently, he is an Associate Professor of Management Science and Engineering at the School of Management, Nanjing University of Posts and Telecommunications. His main research interests include supply chain logistics management, consumer behavior, and supply chain finance.

Mingchuan You received his BSc degree in Information Management and Information Systems from the School of Management in Xuzhou Institute of Technology, China in 2013. Currently, she is pursuing a master's degree in Management Science and
Engineering at the School of Management, Nanjing University of Posts and Telecommunications. Her main research interests include supply chain management, supply chain finance, and risk preference.

Guanghua Han received his $\mathrm{PhD}$ degree in Management from Shanghai Jiao Tong University. Then, he joined National University of Singapore as a research fellow. Currently, he is an Associate Professor at the School of International and Public Affairs, Shanghai Jiao Tong University. Dr. Han has more than 10-year research experience in operations management and has published more than 20 papers in the research field. 